\title{
Nanoclay Nucleation Effect in the Thermal Stabilization of a Polymer Nanocomposite: A Kinetic Mechanism Change.
}

\author{
Pedro E. Sánchez-Jiménez*, Luis A. Pérez-Maqueda, Antonio Perejón, José M. Criado \\ Instituto de Ciencia de Materiales de Sevilla, C.S.I.C.-Universidad de Sevilla, C. Américo \\ Vespucio n49, 41092 Sevilla, Spain
}

\begin{abstract}
The enhanced thermal stability of polymer-clay nanocomposites over the original polymers is one of their most interesting features and it has been profusely studied within the last decades. Here, a thorough kinetic analysis of polystyrene and a montmorillonite-polystyrene nanocomposite has been performed making use of state-of-the-art kinetic procedures. It has been found that the degradation mechanism changes from a chain scission process for the polymer to a complex two step nucleation driven reaction for the nanocomposite. This mechanism change can explain the delayed onset of degradation found in the nanocomposite. Moreover, observation by TEM microscopy has shown that the clay platelets within the composite could act as nucleation centers for the decomposition.
\end{abstract}

Keywords: Composite, Polystyrene, Clay, Montmorillonite, Mechanism, Kinetic Model

\footnotetext{
*Corresponding author. Tel +34954489548 Fax +34954460665
}

e-mail address: pedro.enrique@icmse.csic.es 


\section{Introduction}

In recent decades, a significant effort has been devoted to the development of polymer-clay nanocomposites. These materials manifest very favorable characteristics that, together with a low cost and a wide range of potential technological applications, have attracted a great deal of interest in both industrial and academic areas, with new publications appearing every year. ${ }^{1-10}$ The dispersion of nanometer-sized layered silicates, even at low filler content, within a polymer matrix constitutes an effective way to enhance thermal, mechanical and gas barrier properties as well as the flammability performance as compared to the original polymer $2,11-26$ The significant improvements attained are a consequence of the interaction between the nanoclays, possessing a high specific surface, and the polymer matrix. Apart from conventional phase separated polymer/silicate microcomposites, in which the polymer and the inorganic host remain immiscible, two types of morphologies are possible: intercalated, with the polymer chains inserted into the gallery space between parallel silicate layers without seriously altering the structure; and exfoliated, in which the layered silicate loses its structural integrity and the individual layers become dispersed within the continuous polymer matrix.,12

Determining the mechanism responsible for improving the thermal stability of polymer-clay composites has been the objective of a great number of publications. Traditionally, it has been attributed to a barrier effect produced by the formation of a carbonaceous silicate residue over the molten polymer that hinders the transfer of volatile products from the interior of polymer matrix and, at the same time, reduces the heat transfer., ${ }^{4,5,13,14,27}$ Thus, it has been amply reported that the presence of nanodispersed clay platelets favors the formation of char during the decomposition, even at very low clay loadings. ${ }^{10,20,28}$ This led to the proposal of a radical trapping model that assumes that the structural metals in the clay traps the radicals that form during the polymer degradation, thus slowing down the degradation reaction. ${ }^{29}$ Previous 
studies have reported that intercalated nanocomposites present higher thermal stability than the exfoliated structures, suggesting that the thermal stabilization cannot be attributed exclusively to the dispersion level. ${ }^{30}$ Moreover, in some cases the thermal stability of the composite is unaffected or even worsened by the inclusion of the clay. ${ }^{31-33}$ Thus, both chemical nature and preparation methods must probably play a key role in the thermal stabilization. A series of works by Vyazovkyn's group on the degradation of the polystyreneclay system have demonstrated that the reduced mobility of the polymer chains inside the galleries promotes a nanoconfinement effect that increases the probabilities of interchain and recombination reactions, thereby changing the chemical degradation mechanism. ${ }^{30,34-38}$ This is in agreement with previous models and it could be responsible for the increased char residue. However, despite the important volume of published works there is still much to be learned about the underlying mechanism by which the inclusion of clay improves the thermal stability and influences the decomposition of the polymer.

The objective of this work is to shed new light into the influence that the inclusion of the organoclay exerts on the mechanism of thermal degradation of the polymer. Here, the thermal stability of a Polystyrene-Montmorillonite (PS-MMT) nanocomposite has been approached by investigating the thermal degradation kinetics of the nanocomposite employing some novel analytical methods recently developed, including the simultaneous analysis of experimental data recorded under different heating schedules and a curve deconvolution procedure developed for complex reactions. Apart from the frequently used linear heating and isothermal experiments, constant rate controlled analysis (CRTA) has also been employed. This technique constitutes an alternative approach that has been recently applied to polymer decomposition reactions. ${ }^{39-42}$ In CRTA experiments, the temperature is controlled in such a way that the overall reaction rate is maintained along the entire experiment at a constant value predefined by the user. One of the most prominent advantages of this procedure is that the 
interfering mass and heat transfer phenomena occurring during the reaction are greatly minimized when a slow decomposition rate is used. As a consequence, the results obtained by CRTA are more representative of the forward reaction than those obtained from conventional methods ${ }^{43-45}$ and can be used to discriminate between overlapping steps. ${ }^{46}$ Additionally, the shape of the CRTA experimental curves provides valuable information pertaining to the

reaction mechanism. ${ }^{47}$ In this work, a detailed kinetic description of the thermal degradation of both the pure polystyrene and a PS-MMT intercalated nanocomposite prepared by a solution casting route is presented and the results are compared in order to evaluate the influence of the nanoclay over the degradation mechanisms.

\section{Experimental}

The following materials were used for the preparation of the composites: commercial atactic polystyrene (Goodfellow, powder, product number 261595) and a natural montmorillonite modified with an organic quaternary ammonium salt (Cloisite 20A, Southern Clay). Montmorillonite, MMT, is the preferred and most widely used clay for composite preparation for its high aspect ratio, exchange capacity, surface area and availability.

Nanocomposites were prepared by a sonication-assisted solution casting procedure since atactic polystyrene (PS) can be easily dissolved in toluene. $100 \mathrm{mg}$ of the organicallymodified montmorillonite were initially dispersed in $25 \mathrm{ml}$ of toluene. The clay suspension was then sonicated (Misonix 3000, $20 \mathrm{kHz}$, with a $12.7 \mathrm{~mm}$ diameter probe and an applied power of $45 \mathrm{w}$ ) for 3 hours at $20^{\circ} \mathrm{C}$ in a cylindrical jacketed reactor, with the exterior jacket attached to a recirculator for controlling the reactor temperature. Then, the temperature of the mixture was increased to $80^{\circ} \mathrm{C}$ and two grams of PS, were added to the clay suspension, obtaining a final clay loading of $5 \%$ in weight. The final mixture was further sonicated for 
$5 \mathrm{~h}$. The as-obtained viscous solution was poured onto an aluminium mould, introduced into a vacuum furnace and heated overnight at $80^{\circ} \mathrm{C}$ for solvent removal.

Thermogravimetric (TGA) measurements were performed in a homemade instrument constructed with a high sensitivity CI Electronics thermobalance. A continuous flow of $\mathrm{N}_{2}$ $\left(100 \mathrm{ml} \mathrm{min}^{-1}\right)$ was maintained to assure an inert atmosphere. Small mass samples $(\sim 10 \mathrm{mg})$ were used in order to minimize mass and heat transfer phenomena. Samples were placed on a platinum pan inside a low thermal inertia homemade furnace. Experiments were recorded under linear heating, isothermal and controlled rate thermal analysis. A detailed description of the experimental set up can be found at references. ${ }^{48,49}$

TGA-FTIR analysis was carried out on a TA Instruments Q5000 interfaced with a Jasco FTIR 6100 spectrometer. The experiment was run at a heating rate of $5^{\circ} \mathrm{C} / \mathrm{min}$ under a nitrogen flow rate of $50 \mathrm{cc} / \mathrm{min}$ and the evolved gases were transferred to the FTIR gas cell chamber from the TGA through a heated $\left(200^{\circ} \mathrm{C}\right)$ stainless steel tubing.

DSC measurements were carried out at a linear heating rate of $10 \mathrm{~K} \mathrm{~min}^{-1}$ in a Q200 (TA Instruments). XRD patterns were recorded with a PhillipsX'pert Pro diffractometer equipped with $\mathrm{Cu} \mathrm{K} \alpha$ radiation $(\lambda=1.54053 \mathrm{~nm})$. The scanning was performed over a $2 \Theta$ diffration angle range of $1-30^{\circ}$ at a rate of $0.05^{\circ}$ every 3 seconds. The interlayer mean d-spacing was determined by means of the Bragg's law.

TEM micrographs were taken using a Phillips CM-200 instrument $\left(200 \mathrm{kV}, \mathrm{LaB}_{6}\right.$ filament and $0.28 \mathrm{~nm}$ resolution). 


\section{Results}

\subsection{Characterization of the nanocomposite by DRX, DSC and TGA}

As a consequence of the intercalation of the polystyrene chains, the interlayer space of the organoclay is expanded. Thus, the formation of the composite and the dispersion level of the clay within the polymer matrix can be evaluated by X-Ray diffraction (XRD). Figure 1 displays the XRD diffractograms corresponding to the initial Cloisite20A organoclay and to the prepared PS-Cloi20A nanocomposite. The (001) reflection at $2 \theta=3.62^{\circ}$ in the organoclay diffractogram corresponds to a $\mathrm{d}_{001}$ value of $2.44 \mathrm{~nm}$, as determined using the Bragg's law. On the other hand, in the composite the (001) reflection shifts to a lower angle, $2 \theta=2.22^{\circ}$, corresponding to a $\mathrm{d}_{001}$ value of $3.98 \mathrm{~nm}$. The increased d-spacing shows intercalation of polystyrene chains within the MMT gallery space. The presence of the (001) reflection also implies that no complete exfoliation of the platelets occurred, so that the silicate layers remains, at least partially, in a stacked form, though dispersed within the polymer matrix. Also, the broad nature of the (001) reflection is probably due to the partial disorder of the parallel stacking of the clay layers caused by the extensive polymer insertion. This is further asserted by the loss of the (002) secondary reflection in the nanocomposite diffractogram, that can also be attributed to the disordered structure arising from the partial exfoliation of the clay platelets.

Figure 2 shows the differential scanning calorimetry (DSC) curves recorded for both the original polystyrene and the nanocomposite. The stepwise change in the slope of the curve is due to a variation in the heat capacity produced by the glass transition of the sample. The shift of the glass transition to higher temperatures, from $83^{\circ} \mathrm{C}$ to $88^{\circ} \mathrm{C}$, further confirms the formation of an intercalated composite. As it has been reported in the literature, the mobility 
restrictions imposed over the polymer chains due to the confinement within the galleries induce such a displacement in temperature of glass transition. ${ }^{34,38,50}$

The differences in the thermal degradation behavior of the pure polymer and the PS-Cloi20A nanocomposite were studied by TGA. Figure 3a shows the mass loss and the rate of mass loss profiles against the temperature obtained for the thermal degradation of PS and PS-Cloi20A under linear heating rate conditions $\left(5 \mathrm{~K} \mathrm{~min}^{-1}\right)$. As shown in the figure, the onset of degradation shifts towards higher temperatures upon the inclusion of the clay. A change in the shape of the degradation curves is also noticeable. Thus, the degradation of the nanocomposite seems to occur in a more abrupt fashion, in a narrow range of temperatures, whereas the degradation of the pure polystyrene extends over a much wider range. This feature is even more evident in the time-derivative plots. The onset of degradation of the nanocomposite is delayed around $30 \mathrm{~K}$ with respect to the pure polystyrene, but soon, the degradation accelerates achieving a much higher rate of mass loss. Furthermore, the temperature of complete decomposition is slightly lower than that of the pure polystyrene. Such observation is consistent with the isothermal experiments displayed in Figure 3b, recorded at a temperature of $593 \mathrm{~K}$. It can be noticed that the onset of degradation of the composite is effectively delayed, with no significant mass loss occurring during the first 4050 minutes after the isothermal temperature is reached. Then, once the mass loss starts, it goes at an accelerated pace, reaching the complete degradation much before the pure polystyrene. This effect is characteristic of nucleation driven mechanisms, which imply that the process starts at discrete points (nuclei) from which it extends into the rest of the material. It should be mentioned that the isotherm corresponding to the pure polystyrene also presents an acceleratory nature, but that is not readily evident in Figure $3 b$ due to scaling issues. Anyway, a careful look at the DTG curve will reveal a maximum at around $25 \%$ mass loss, which has been labeled for clarity. 
It has been recently proven that the shape of curves recorded under constant rate thermal analysis provides fundamental information regarding the nature of a reaction. ${ }^{47}$ Figure 4 shows the temperature and conversion profiles against time obtained from the degradation of polystyrene and the PS-Cloi20A composite at a constant reaction rate of $0.001 \mathrm{~min}^{-1}$. In these experiments, the system is heated until the predefined reaction rate is reached, and thereafter the temperature is controlled in such a way that the reaction rate is maintained constant. For a more accurate comparison both experiments were planned so that the total experimental times are the same. The linearity of the plot of the conversion against time (squares and circles for PS and PS-Cloi20A respectively) clearly demonstrates the reaction rate is maintained at a constant value. The experimental curves recorded under CRTA conditions evidence significant differences in the degradation behavior of polystyrene and the PS-Cloi20A composite. The evolution of temperature with time displays in both cases an initial "induction" period, after which the degradation accelerates (acceleratory period), forcing the system to cool down in order to keep the reaction rate under control. This feature is typical of processes in which the reaction rate is controlled either by a nucleation and growth of nuclei ${ }^{51}$ or by a chain scission mechanism ${ }^{47}$, producing a minimum in the CRTA temperature-time profile. The sudden reaction acceleration, responsible of the subsequent cooling, takes place at a higher temperature, and is more pronounced in the curve corresponding to the decomposition of the PS-Cloi20A nanocomposite. This effect is in concordance with the linear heating experiments shown in Figure 3a, where a higher reaction rate is achieved after a delayed start. It is also worth mentioning that Figure 4 shows that once the acceleratory period is over, the temperature required to maintain the preset reaction rate is slightly lower for the PS-Cloi20A composite than for the pure polystyrene. Again, this is in agreement with the linear heating and isothermal experiments which showed that whereas the onset of degradation of the composite is delayed, the complete decomposition of the material is 
hastened. Thus, the comparison of the degradation curves recorded under linear heating, isothermal and constant rate conditions all suggest a change in the kinetic model obeyed by the process and, consequently, in the mechanism of degradation for the composite as compared with the pristine polystyrene.

\subsection{Monitoring the degradation products by TGA-FTIR}

For gaining further information regarding the degradation processes, the gases evolved during the decomposition of polystyrene and the PS-Cloi20A composite were followed using a coupled TGA-FTIR equipment. The spectrograms in Figure 5 show clear differences in the composition of the degradation products in both cases, supporting the idea of a change in the degradation mechanism. ${ }^{52,53}$ The spectra included in the figure were taken at the time when the degradation rate is at its maximum value and, therefore, the amount of volatiles produced is at its peak. The most prominent difference between the polystyrene and PS-Cloi20A is found in a new band appearing at $2950 \mathrm{~cm}^{-1}$ during the decomposition of the composite. Such band is characteristic of $\mathrm{C}-\mathrm{H}$ stretching in methyl or methylene groups and it has been attributed to the formation of $\alpha$-methylstyrene. ${ }^{36,52}$ There are also differences in the intensity ratio of several bands at $1450-1490 \mathrm{~cm}^{-1}$, and below $1000 \mathrm{~cm}^{-1}$. Likewise, the pair of bands at 1600 (benzene ring breating) and $1630 \mathrm{~cm}^{-1}(\mathrm{C}=\mathrm{C}$ stretching in the vinyl group) observed for the composite are reversed in the case of pure polystyrene. ${ }^{54}$

Figure 6 shows the evolution of the FTIR spectra as a function of degradation time for the case of the PS-Cloi20A composite. It can be noticed how the relative intensities of several bands change along the reaction progress. The change is especially significant for the bands at $3100 \mathrm{~cm}^{-1}\left(\mathrm{sp}^{2} \mathrm{C}-\mathrm{H}\right.$ aromatic stretching in the benzene rings) and $2950 \mathrm{~cm}^{-1}$. The former appears at shorter times but fades away much before the latter. On the other hand, the same experiment was carried out for pure polystyrene and no variation in the relative intensities of 
the different modes were detected during the degradation process. This observation supports the hypothesis of a change in the degradation mechanism for the composite as compared with the pristine polystyrene.

\subsection{Isoconversional and Combined Kinetic Analysis of polystyrene}

Figure 7 shows the experimental $\alpha$-T plots recorded for the thermal degradation of polystyrene under linear heating rate (7a) and sample controlled (7b) conditions. The reacted fraction, $\alpha$, is expressed as $\alpha=\left(w_{0^{-}} w\right) /\left(w_{0}-w_{f}\right)$, where $\mathrm{w}_{0}$ is the initial mass, $\mathrm{w}_{\mathrm{f}}$ the residual char and $w$ the sample mass at an instant $t$. Linear heating rate experiments were carried out at $0.5,1,2$ and $5 \mathrm{~K} \mathrm{~min}^{-1}$ whereas sample controlled experiments were recorded at the constant reaction rate of $0.001 \mathrm{~min}^{-1}$. The apparent activation energy of the degradation as a function of the reacted fraction was calculated by means of the Friedman isoconversional method. ${ }^{55-57}$ The method is based in the following equation:

$$
\ln \left(\frac{d \alpha}{d t}\right)=\ln (A f(\alpha))-\frac{E}{R T}
$$

where $A$ is the Arrhenius pre-exponential factor, $R$ is the gas constant, $E$ the apparent activation energy, $\alpha$ the reacted fraction, $T$ is the process temperature and $f(\alpha)$ is the kinetic model that accounts for the reaction rate dependence on $\alpha$. The kinetic model or conversion function is an algebraic expression which is usually associated with a physical model that describes the kinetics of the solid state reaction. ${ }^{58}$ Eq. (1) is a general expression that describes the relationship among the reaction rate, reacted fraction and temperature independently of the thermal pathway used for recording the experimental data. Thus it can be simultaneously applied to experimental data obtained under different heating schedules.

The apparent activation energy for a given value of $\alpha$ is determined from the slope of the plot of the left hand side of Eq. (1) against the inverse of the temperature. Figure 8 presents the 
evolution of the apparent activation energy with the conversion. The calculated activation energies are sustained by significant values of the correlation coefficient, over 0.99 . It is clear that the apparent activation energy stays constant during the whole process, averaging $204 \mathrm{~kJ}$ $\mathrm{mol}^{-1}$. Such energy is within the range of values reported in literature. ${ }^{38,59,60}$. The invariant activation energy and the clean degradation curves in Figure 7 suggest that the degradation of polystyrene is a single step process.

In order to determine the kinetic model and the pre-exponential factor, the experimental curves in Figure 7 were also analysed using the Combined Kinetic Analysis methodology. 61,62 The method is based in the following equation:

$$
\ln \left(\frac{d \alpha / d t}{f(\alpha)}\right)=\ln A-\frac{E}{R T}
$$

The plot of the left hand side of Eq. (2) versus the inverse of the temperature will yield a straight line if the proper $f(\alpha)$ is considered for the analysis. The apparent activation energy is determined from the slope of such plot, while the intercept leads to the pre-exponential factor. An empirical fitting function with the form $\alpha^{n}(1-\alpha)^{m}$ is employed as the conversion function $f(\alpha)$. Such function can fit every kinetic model proposed for solid state reactions and, at the same time, accounts for possible deviations from the ideal kinetic models due to factors such as inhomogeneity in particle size and shapes. ${ }^{62}$ The Pearson linear correlation coefficient between the left hand side of Eq. (2) and the inverse of the temperature is set as an objective function for optimization. By means of the maximize function of the software Mathcad, parameters $n$ and $m$ that yield the best linear correlation are obtained, and the corresponding values of $E$ and $A$ are calculated. Figure 9 shows the plot of the left hand side of Eq. (2) versus the reciprocal temperature. The optimization procedure shows that experimental data from all the curves in Figure 7 can be fitted simultaneously into a single straight line, with a 
correlation coefficient of 0.999 , when the conversion function $f(\alpha)$ takes the form $\alpha^{0.28}(1-$ $\alpha)^{0.901}$. The slope of the plot leads to an apparent activation energy value of $204 \pm 1 \mathrm{~kJ} \mathrm{~mol}^{-1}$ and the intercept to an Arrhenius preexponential factor of $(2.7 \pm 0.3) 10^{15} \mathrm{~min}^{-1}$. In Figure 10 the $f(\alpha)$ function deducted from the combined analysis, $\alpha^{0.28}(1-\alpha)^{0.901}$, is compared with some of the most widely used conversion functions the literature. ${ }^{40,58}$ The functions are normalized at $f(0.5)$ for better distinguish the different plots. It is clear that the estimated $f(\alpha)$ function and the theoretical curves corresponding to random scission models match closely. A random scission mechanism implies the cleavage of the polymeric chains followed by the release of fragments once they become small enough to volatilize. Such mechanism suits nicely the degradation of polystyrene which has been claimed to proceed by scission of the main chains followed by depolymerisation into monomers and oligomers. ${ }^{37,52}$ Moreover, this result is also concordant with the information extracted from the shape of the CRTA curve since it has been recently demonstrated that random scission driven reactions exhibit under such experimental conditions a temperature minimum at $\alpha=0.25$ in the temperature-conversion profile, ${ }^{47}$ which is exactly the value at which the minimum is located in the experimental curve in Figure $7 \mathrm{~b}$ and the maximum of the DTG curve of the isothermal experiment in Figure 3b. It should be noted that the conclusion of chain scission as the model driving polystyrene degradation has been reached without any previous assumption whatsoever regarding the kinetic model and that experimental data recorded under different thermal schedules all lead to a similar result. A useful method for validating the kinetic parameters calculated by the analysis is the reconstruction of the original experimental curves simulating a set of curves assuming such kinetic parameters and heating conditions identical as those used in the experiments. The simulations were performed by means of a $4^{\text {th }}$ order numerical integration Runge-Kutta method. As the curves in Figure 7 show, the reconstructed (simulated) curves and the experimental ones match closely. 
A similar approach was initially employed to study the degradation of the PS-Cloi20A nanocomposite. The experimental curves were recorded under heating conditions identical as those used in the case of the pure polystyrene. Thus, figure 11 shows the experimental curves recorded for the thermal degradation of PS-Cloi20A under linear heating rate (11a) and sample controlled (11b) conditions. Linear heating rate experiments were carried out at 0.5 , 1.0, 2.0 and $5.0 \mathrm{~K} \mathrm{~min}^{-1}$ while sample controlled experiments were recorded under a constant reaction rate of $0.001 \mathrm{~min}^{-1}$. Figure 8 shows the evolution of the activation energy with the conversion as determined by means of the Friedman Isoconversional method described in the previous section. While the correlation factors of the Friedman plots are significant, the apparent activation energy is not constant but increases steadily from $155 \mathrm{~kJ} \mathrm{~mol}^{-1}$ to almost $200 \mathrm{~kJ} \mathrm{~mol}^{-1}$. Whereas this effect could be due to several factors, the irregular shape of the CRTA curve in Figure 4 supports the hypothesis of a complex process where more than one reaction, each described by a different kinetic equation, are involved. This is in agreement with the TG-FTIR analysis presented above that showed that the relative intensities of several bands change along the reaction progress. Moreover, since the evolution of the relative intensities of the different bands did not seem to be affected by the heating rate, it could be considered that the involved processes are not competitive but independent.

No single set of kinetic parameters was able to fit the whole set of experimental data simultaneously into a straight line supporting the complex nature of the process. In a recent work, a procedure extended the Combined Kinetic Analysis to complex reactions composed of overlapping stages. ${ }^{63}$ If two independent stages occurring simultaneously are assumed, each individual process would be described by a different kinetic equation with a set of different kinetic parameters, whereas the total reaction rate will be the result of the addition of 
the reaction rates that correspond to the different processes, each of them multiplied by their contribution factor. Thus the total reaction rate can be written as follows:

$$
\frac{d \alpha}{d t}=l_{1} c_{1} A_{1} \exp \left(-E_{1} / R T\right) \alpha_{1}^{m_{1}}\left(1-\alpha_{1}\right)^{n_{1}}+l_{2} c_{2} A_{2} \exp \left(-E_{2} / R T\right) \alpha_{2}^{m_{2}}\left(1-\alpha_{2}\right)^{n_{2}}
$$

where $l_{1}$ and $l_{2}$ are the contributions to the overall reaction of the first and second processes, respectively. $A_{1}, E_{1}, n_{1}$, and $m_{1}$ are the preexponential factor, activation energy and coefficients corresponding to the first process, while $A_{2}, E_{2}, n_{2}$, and $m_{2}$ are the kinetic parameters and coefficients of the second process. An iterative optimization process, which is described in detail in the original work, ${ }^{63}$ is then applied, leading to the following kinetic parameters: $l_{1}=0.57, E_{1}=155.2 \mathrm{~kJ} \mathrm{~mol}^{-1},\left(c_{1} A_{1}\right)=2.010^{12} \mathrm{~min}^{-1}, n_{1}=0.720, \mathrm{~m}_{1}=0.778, l_{2}=$ $0.43, E_{2}=198.4 \mathrm{~kJ} \mathrm{~mol}^{-1},\left(c_{2} A_{2}\right)=6.210^{15} \mathrm{~min}^{-1}, n_{2}=0.922$, and $m_{2}=0.834$. The apparent activation energies obtained for the two contributing stages agree with the rising trend observed by Friedman results (Figure 8). Thus, while the overall contribution of the two stages is roughly similar $\left(l_{1}=0.57\right.$ and $\left.l_{2}=0.43\right)$ the contribution of the first step at low alpha values must be higher because the overall apparent activation energy approach that of the first stage. The reverse is true for the higher end of the conversion range, when the overall activation energy is closer to that estimated for the second reaction. In figure 12 the empirical $f(\alpha)$ functions for each contributing step are compared with the $f(\alpha)$ functions corresponding to the several theoretical models. It is evident that both steps approach closely a nucleation and growth Avrami-Erofeev kinetic model. In the same way as was done in the previous section for the case of polystyrene, the kinetic parameters calculated by the kinetic analysis were used for reconstructing the experimental curves. The simulations were performed by means of the Runge-Kutta method, and the resulting curves are included in figure 11. The kinetic parameters are validated by the close match between the simulated curves and the original experimental ones. Thus, it appears that the inclusion of the clay modifies the degradation 
mechanism, changing it from a random scission driven to a complex mechanism involving two nucleation stages. Additionally, in Figure 13 the experimental DTG curve corresponding to the degradation of the PS-Cloi20A nanocomposite is compared with the DTG curve obtained by the addition of the DTG curves corresponding to each of the contributing steps. The DTG curves of the deconvolved steps were simulated using the kinetic parameters deduced from the Combined Kinetic Analysis described in this section. For reasons of brevity, only the curve recorded at $2 \mathrm{~K} \mathrm{~min}^{-1}$ is included here. The reconstruction is reasonably good, given the difficulty of the system, showing that the contributing steps take place almost simultaneously. Nevertheless, the second step, described by the higher activation energy, appears at a slightly higher temperature.

\section{Discussion}

The results here obtained from the kinetic study indicating that the inclusion of the nanoclay modifies the degradation mechanism of the nanocomposite are in agreement with degradation studies by cone calorimetry that have shown for polystyrene nanocomposites a significantly smaller total heat release than the pure polymer. ${ }^{12,29,64}$ Similarly, a smaller enthalpy for the decomposition of the nanocomposite as compared with that of the pure polymer have been obtained by calorimetric analysis. ${ }^{38}$ Further studies by Pyrolysis-GC-MS and TGA-FTIR methods have shown a change in the degradation products. Thus, it was detected an abnormally high yield of $\alpha$-methylstyrene, attributed to an enhancement of intermolecular interactions, for a polystyrene-clay nanocomposite as compared with the pure polymer. ${ }^{37,52}$

Similar differences are observed in the FTIR spectra of the volatiles produced during the degradation of polystyrene and the composite prepared in this work, as shown in Figure 5. However, it can also be noticed that while the relative intensities of the different modes during the degradation of pure polystyrene are maintained constant during the whole process, 
such thing does not happen in the case of the nanocomposite, with the relative intensities changing with the reaction time (Figure 6). It can be inferred from that difference that the polystyrene decomposition can be described by a single mechanism while the degradation of the composite involves more than one mechanisms or processes, each yielding different products. Figure 14 shows the evolution of the intensities of the bands at $3100 \mathrm{~cm}^{-1}$ and 2950 $\mathrm{cm}^{-1}$ forming during PS-Cloi20A degradation with the reaction time. It is clear that both bands follow roughly similar trends. However, the $3100 \mathrm{~cm}^{-1}$ band is stronger than the $2950 \mathrm{~cm}^{-1}$ band at lower reaction times but it turns weaker after the maximum reaction rate point is passed. Thus, FTIR spectra suggests the process becomes more complex which is in agreement with the results obtained by the kinetic analysis, indicating that the single chain scission driven degradation process of the polystyrene turns into a complex two step mechanism based on the formation and growth of nuclei (which are probably degradation centers in this case) when the clay is added. The kinetic study and evolution of the bands in Figure 14 also indicate that the two pathways are independent and coexist along the whole process. A nucleation driven mechanism entails an initial "induction" time due to formation of the nuclei, followed by an acceleration of the reaction when it extends into the rest of the material. This is clearly evidenced by the CRTA and isothermal experiments in Figures $3 \mathrm{~b}$ and 4. Thus, it is the mechanism change what is ultimately responsible of the thermal stabilization of the nanocomposite, delaying the start of the decomposition due to the slow formation of the nuclei from which the process eventually propagates. The nucleation mechanism brings important implications at a practical level because if the materials undergoes any high temperatures event during processing or any other application, the nucleation can already be initiated (even if no significant mass loss is detected) and the degradation will be hastened when it is again exposed at high temperatures (Figure 3b). 
Previous reports have shown by Atomic Force Microscopy that clay platelets can act as nucleation centers during crystallization processes. ${ }^{65} \mathrm{~A}$ similar situation could occur in polymer-clay composites in term of degradation, with the platelets acting as degradation centers. It is well known that when polymer chains intercalate in the nanoclays galleries, it produces a confinement effect that severely restricts the mobility of the chains. ${ }^{66,67}$ This restriction is manifested in changes in some physical properties such as the glass transition temperature as shown in Figure 2. It has been reported that in confinement, adhesion effects between confining material and polymer chains gain importance. Also, the reduced space favors a higher degree of ordering of the polymer chains due to a higher interaction level between nearby chains. In every case, a loss of mobility is a probable outcome. The change into a nucleation mechanism could be rationalized by the hindering effect brought by the lower mobility and higher interchain interaction of such confined system, which would hinder the release of the small fragments produced by the scission of the polymeric chains. It should be noted at this point that, in TGA experiments, until those fragments finally volatilizes they will not be detected as mass lost. It has also been claimed that the intensity of the FTIR absorption band ( $\mathrm{sp}^{3}$ carbon-hydrogen stretching vibration) at $2950 \mathrm{~cm}^{-1}$, assigned to $\alpha$ methylstyrene, increases with the clay content whereas the carbon-carbon double bond stretching at $1630 \mathrm{~cm}^{-1}$ and the $\mathrm{C}-\mathrm{H}$ out-of-plane deformations at 990 and $910 \mathrm{~cm}^{-1}$ decreases. ${ }^{52}$ This brings the idea of the intercalation into the clay galleries being directly responsible of one of the parallel steps since an increasing amount of clay would strengthen the pathway directly related to the formation of $\alpha$-methylstyrene. This could be due to the confinement effects favoring interchain radicalary reactions or due to a direct interaction between the MMT layers and the polymer. However, an alternative explanation can be found in the works carried out by Vyazovkin's group on the degradation of polystyrene-clay composites where the polystyrene forms brush structures. There, the interaction between PS 
and the clay is considered minimal and the proximity of the PS chains due to the nanoconfinement is regarded as the main factor for the mechanism change. ${ }^{36}$

In order to validate the aforementioned theory, the evolution of the composite during the decomposition has been followed by TEM and EDX. Figure 15 includes three TEM micrographs showing the nanocomposite at three different stages of degradation. Figure 15a displays a nanoclay platelet dispersed within the polymeric matrix in the initial composite. Figure $15 \mathrm{~b}$ shows the composite after $20 \%$ of the initial mass loss has been lost due to the composite degradation. It can be seen how small residue aggregates coming from the polymer degradation appears over the clay. Lastly, figure $15 \mathrm{c}$ corresponds to the nanocomposite after a $60 \%$ mass loss. In this picture, the residual particles produced as final product of the thermal decomposition of the polymer are clearly observed. The fact that the EDX compositional analysis points out not only the presence of the carbon, but some amounts of $\mathrm{Si}, \mathrm{O}$, and $\mathrm{Al}$ due to the clay (Figure 15d) seems to demonstrate that residue is formed in intimate contact with the clay particles. These results suggest that the nanoclay platelets act as nucleation centers from which the degradation extends into the rest of the material, supporting the nucleation and growth kinetic mechanism determined by the kinetic analysis.

\section{Conclusion}

Here, the improved thermal stability of a clay-polystyrene nanocomposite has been studied under a kinetic approach. Thus, the kinetic equations describing the thermal decomposition of the pure polystyrene and the nanocomposite have been determined by means of the combined kinetic analysis and Friedman isoconversional methods. It has been found that the inclusion of the clay modifies the degradation mechanism of the composite with respect to that of the polystyrene, changing from a simple random scission driven process to a two stage nucleation controlled mechanism. In the latter case, the kinetic parameters and the contribution of each 
step to the overall reaction has also been determined. The results are supported by the FTIR spectra of the evolved gases released during the decomposition of polystyrene and the PSCloi20A nanocomposite. Polystyrene shows constancy in the relative intensity of the FTIR bands along the whole process, suggesting a single step reaction. On the other hand, the relative intensities of the absorption bands appearing during the composite degradation vary with the reaction time, suggesting a complex multistep mechanism. Finally, such mechanism change is likely to be responsible of the increased stability of the composite since nucleation is an acceleratory mechanism that needs the formation of degradation centers before the degradation propagates through the bulk of the material. Observation by TEM and EDX analysis of partially decomposed samples confirms that the nanoclay platelets may act as nucleation centers during the decomposition.

\section{ACKNOWLEDGEMENT}

Financial support from projects TEP-03002 from Junta de Andalucía, CTQ2011-27626 from the Spanish Ministerio de Economía y Competitividad and FEDER funds is acknowledged. Additionally, one of the authors (PESJ) is supported by a JAE-Doc grant (CSIC-FSE).

\section{References}

(1) Okada, A.; Usuki, A. Macromol. Mater. Eng. 2006, 291, 1449-1476.

(2) Alexandre, M.; Dubois, P. Mat. Sci. Eng. R. 2000, 28, 1-63.

(3) Sudhakara, P.; Kannan, P.; Obireddy, K.; Rajulu, A. V. J. of Mater. Sci. 2011, 46, 2778-2788.

(4) Zanetti, M.; Lomakin, S.; Camino, G. Macromol. Mater. Eng. 2000, 279, 1-9.

(5) Manias, E.; Touny, A.; Wu, L.; Strawhecker, K.; Lu, B.; Chung, T. C. Chem. Mater. 2001, 13, 3516-3523.

(6) Tjong, S. C. Mat. Sci. Eng. R. 2006, 53, 73-197.

(7) Krishna, S. V.; Pugazhenthi, G. J. Appl. Polym. Sci. 2011, 120, 1322-1336.

(8) Morales-Gamez, L.; Franco, L.; Puiggali, J. Thermochim. Acta 2011, 512, 142-149.

(9) Ray, S. S.; Okamoto, M. Prog. Polym. Sci. 2003, 28, 1539-1641.

(10) Pavlidou, S.; Papaspyrides, C. D. Prog. Polym. Sci. 2008, 33, 1119-1198. 
(11) Giannelis, E. P.; Krishnamoorti, R.; Manias, E. Polymer-Silicate Nanocomposites: Model Systems in Confined Polymers. In Polymers in Confined Environments; Springer, 1999. 138, p107-147.

(12) Gilman, J. W. Appl. Clay Sci. 1999, 15, 31-49.

(13) Gilman, J. W.; Jackson, C. L.; Morgan, A. B.; Harris, R.; Manias, E.; Giannelis, E. P.; Wuthenow, M.; Hilton, D.; Phillips, S. H. Chem. Mater. 2000, 12, 1866-1873.

(14) Choudalakis, G.; Gotsis, A. D. Eur. Polym. J. 2009, 45, 967-984.

(15) Lepoittevin, B.; Devalckenaere, M.; Pantoustier, N.; Alexandre, M.; Kubies, D.; Calberg, C.; Jerome, R.; Dubois, P. Polymer 2002, 43, 4017-4023.

(16) Lepoittevin, B.; Pantoustier, N.; Devalckenaere, M.; Alexandre, M.; Calberg, C.; Jerome, R.; Henrist, C.; Rulmont, A.; Dubois, P. Polymer 2003, 44, 2033-2040.

(17) Zanetti, M.; Camino, G.; Canavese, D.; Morgan, A. B.; Lamelas, F. J.; Wilkie, C. A. Chem. Mater. 2002, 14, 189-193.

(18) Joseph, S.; Focke, W. W. Polym. Composite 2011, 32, 252-258.

(19) Peeterbroeck, S.; Alexandre, M.; Jerome, R.; Dubois, P. Polym. Degrad. Stabil. 2005, 90, 288294.

(20) Kiliaris, P.; Papaspyrides, C. D. Prog. Polym. Sci. 2010, 35, 902-958.

(21) Hu, Y.; Wang, S. F.; Ling, Z. H.; Zhuang, Y. L.; Chen, Z. Y.; Fan, W. C. Macromol. Mater. Eng. $2003,288,272-276$.

(22) Bourbigot, S.; Duquesne, S.; Jama, C. Macromol. Symp. 2006, 233, 180-190.

(23) Isitman, N. A.; Gunduz, H. O.; Kaynak, C. Polym. Degrad. Stabil. 2009, 94, 2241-2250.

(24) Shanmuganathan, K.; Deodhar, S.; Dembsey, N. A.; Fan, Q. G.; Patra, P. K. Polym. Eng. Sci. $2008,48,662-675$.

(25) Qin, H. L.; Zhang, S. M.; Zhao, C. G.; Hu, G. J.; Yang, M. S. Polymer 2005, 46, 8386-8395.

(26) Tang, Y.; Lewin, M. Polym. Degrad. Stabil. 2008, 93, 1986-1995.

(27) Hossain, M. D.; Yoo, Y.; Lim, K. T. J. Appl. Polym. Sci. 2011, 119, 936-943.

(28) Leszczynska, A.; Njuguna, J.; Pielichowski, K.; Banerjee, J. R. Thermochim. Acta 2007, 453, 7596.

(29) Zhu, J.; Uhl, F. M.; Morgan, A. B.; Wilkie, C. A. Chem. Mater. 2001, 13, 4649-4654.

(30) Chen, K.; Wilkie, C. A.; Vyazovkin, S. J. Phys. Chem. B 2007, 111, 12685-12692.

(31) Leszczynska, A.; Njuguna, J.; Pielichowski, K.; Banerjee, J. R. Thermochim. Acta 2007, 454, 1-

22.

(32) Chrissafis, K.; Antoniadis, G.; Paraskevopoulos, K. M.; Vassiliou, A.; Bikiaris, D. N. Compos. Sci. Technol. 2007, 67, 2165-2174.

(33) Chang, J. H.; An, Y. U.; Sur, G. S. J. Polym. Sci. Pol. Phys. 2003, 41, 94-103.

(34) Vyazovkin, S.; Dranca, I. J. Phys. Chem. B 2004, 108, 11981-11987. 
(35) Chen, K.; Dranca, I.; Vyazovkin, S. Abstr Pap. Am. Chem. S. 2006, 231.

(36) Chen, K.; Susner, M. A.; Vyazovkin, S. Macromol. Rapid Comm. 2005, 26, 690-695.

(37) Chen, K.; Vyazovkin, S. Macromol. Chem. Physic. 2006, 207, 587-595.

(38) Vyazovkin, S.; Dranca, I.; Fan, X. W.; Advincula, R. J. Phys. Chem. B 2004, 108, 11672-11679.

(39) Sanchez-Jimenez, P. E.; Perez-Maqueda, L. A.; Perejon, A.; Criado, J. M. Polym. Degrad. Stabil 2009, 94, 2079-2085.

(40) Sanchez-Jimenez, P. E.; Perez-Maqueda, L. A.; Perejon, A.; Criado, J. M. Polym. Degrad. Stabil. $2010,95,733-739$.

(41) Sanchez-Jimenez, P. E.; Perejon, A.; Criado, J. M.; Dianez, M. J.; Perez-Maqueda, L. A. Polymer 2010, 51, 3998-4007.

(42) Arii, T.; Ichihara, S.; Nakagawa, H.; Fujii, N. Thermochim. Acta 1998, 319, 139-149.

(43) Koga, N.; Criado, J. M. Intern. J. Chem. Kin. 1998, 30, 737-744.

(44) Rouquerol, J. J. Therm. Anal. Cal. 2003, 72, 1081-1086.

(45) PerezMaqueda, L. A.; Ortega, A.; Criado, J. M. Thermochim. Acta 1996, 277, 165-173.

(46) Sanchez-Jimenez, P. E.; Perez-Maqueda, L. A.; Crespo-Amoros, J. E.; Lopez, J.; Perejon, A.; Criado, J. M. Anal. Chem. 2010, 82, 8875-8880.

(47) Sánchez-Jiménez, P. E.; Pérez-Maqueda, L. A.; Perejón, A.; Criado, J. M. Polym. Degrad. Stabil 2011, 96.

(48) Dianez, M. J.; Perez-Maqueda, L. A.; Criado, J. M. Review Sci. Inst. 2004, 75, 2620-2624.

(49) Criado, J. M.; Perez-Maqueda, L. A.; Dianez, M. J.; Sanchez-Jimenez, P. E. J. Therm. Anal. Cal. 2007, 87, 297-300.

(50) Schadler, L. S. Polymer-based and Polymer-filled Nanocomposites. In Nanocomposite Science and Technology; Ajayan, P. M., Schadler, L. S., Braun, P. V., Eds.; Wiley-VCH, 2003; pp 77.

(51) Koga, N.; Kimizu, T. J. Am. Ceram. Soc. 2008, 91, 4052-4058.

(52) Jang, B. N.; Wilkie, C. A. Polymer 2005, 46, 2933-2942.

(53) Vyazovkin, S.; Dranca, I.; Fan, X. W.; Advincula, R. Macrom. Rapid Com. 2004, 25, 498-503.

(54) Vyazovkin, S.; Dranca, I.; Fan, X. W.; Advincula, R. Abstr. Pap. Am. Chem. S. 2004, 227, U559U559.

(55) Friedman, H. L. J. Polym. Sci. C-Polym. Symp. 1964, 183-\&.

(56) Criado, J. M.; Sanchez-Jimenez, P. E.; Perez-Maqueda, L. A. J. Therm. Anal. Cal. 2008, 92, 199203.

(57) Vyazovkin, S.; Burnham, A. K.; Criado, J. M.; Perez-Maqueda, L. A.; Popescu, C.; Sbirrazzuoli, N. Thermochim. Acta 2011, 520, 1-19.

(58) Khawam, A.; Flanagan, D. R. J. Phys. Chem. B 2006, 110, 17315-17328.

(59) Encinar, J. M.; Gonzalez, J. F. Fuel Process. Technol. 2008, 89, 678-686. 
(60) Brems, A.; Baeyens, J.; Beerlandt, J.; Dewil, R. Resour. Conserv. Recy. 2011, 55, 772-781.

(61) Perez-Maqueda, L. A.; Criado, J. M.; Malek, J. J. Non-Cryst. Solids 2003, 320, 84-91.

(62) Perez-Maqueda, L. A.; Criado, J. M.; Sanchez-Jimenez, P. E. J. Phys. Chem. A 2006, 110, $12456-12462$.

(63) Perejon, A.; Sanchez-Jimenez, P. E.; Criado, J. M.; Perez-Maqueda, L. A. J. Phys. Chem. B 2011, $115,1780-1791$.

(64) Morgan, A. B.; Chu, L. L.; Harris, J. D. Fire Mater. 2005, 29, 213-229.

(65) Strawhecker, K. E.; Manias, E. Macromolecules 2001, 34, 8475-8482.

(66) Park, J. Y.; McKenna, G. B. Phys. Rev. B 2000, 61, 6667-6676.

(67) Schonhals, A.; Goering, H.; Schick, C.; Frick, B.; Zorn, R. Eur. Phys. J. E 2003, 12, 173-178. 


\section{FIGURE CAPTIONS}

Figure 1. XRD diffractograms of the organophilic Cloisite 20A and PS-Cloi20A nanocomposite.

Figure 2. DSC curves corresponding to polystyrene and the PS-Cloi20A nanocomposite.

Figure 3. Comparison between the TGA curves corresponding to the degradation of pristine polystyrene and the nanocomposite PS-Cloi20A under (a) linear heating rate at $5 \mathrm{~K} \mathrm{~min}^{-1}$ and (b) isothermal conditions at $593 \mathrm{~K}$. The solid and the dotted lines correspond to the integral TG (mass loss) and to the differential (reaction rate) curves respectively. The maximum of the DTG curve corresponding to the polystyrene degradation has been labeled for clarity.

Figure 4. Thermal decompostition curves of polystyrene (solid line) and the nanocomposite PSCloisite20A (dotted line), recorded under CRTA experimental conditions at a constant reaction rate of $0.001 \mathrm{~min}^{-1}$. The conversion versus time plots are shown as symbols.

Figure 5. FTIR spectra of the evolved products released during the degradation of pure polystyrene and the composite PS-Cloi20A.

Figure 6. FTIR spectra of the evolved products released during the degradation of the nanocomposite PS-Cloi20A as a function of the reaction time.

Figure 7. Thermal decompostition curves of polystyrene (symbols) corresponding to experiments run under (a) linear heating rate and (b) controlled rate conditions. The solid lines correspond to the curves reconstructed using the kinetic parameters obtained from the combined kinetic analysis in Section 3.3. 
Figure 8. Apparent activation energies at different conversion values as determined by the Friedman isoconversional method using experimental data from the degradation curves included in Figures 7 and 11.

Figure 9. Results of the Combined Kinetic Analysis of the polystyrene degradation curves in figure 7. All the experimental data fits to a straight line when the following kinetic parameters are used: $f(\alpha)=\alpha^{0.28}(1-\alpha)^{0.901}, \mathrm{E}=204 \mathrm{~kJ} \mathrm{~mol}^{-1}$ and $\mathrm{A}=2.710^{15} \mathrm{~min}^{-1}$.

Figure 10. Comparison of the $f(\alpha)$ functions (lines) normalized at $\alpha=0.5$ corresponding to some of the most widely used ideal kinetic models with the $f(\alpha)$ equation (circles), $\alpha^{0.28}(1-\alpha)^{0.901}$, as determined for the thermal decomposition of polystyrene by the Combined Kinetic Analysis.

Figure 11. Thermal decompostition curves of the nanocomposite PS-Cloi20A (symbols) corresponding to experiments run under (a) linear heating rate and (b) controlled rate conditions. The solid lines correspond to the curves reconstructed using the kinetic parameters obtained from the combined kinetic analysis performed in Section 3.4.

Figure 12. Comparison of the $f(\alpha)$ functions (lines) normalized at $\alpha=0.5$ corresponding to some of the most widely used ideal kinetic models with the $f(\alpha)$ equations (symbols) determined for the first and second stages composing the degradation of the PS-Cloi20A composite, that is $\alpha^{0.720}(1-\alpha)^{0.778}$ and $\alpha^{0.922}(1-\alpha)^{0.834}$ respectively.

Figure 13. Comparison between the experimental curve corresponding to the complex degradation of the PS-Cloi20A nanocomposite (open circles) and the reconstructed DTG curve (solid lines) obtained by the addition of the DTG curves deduced for each contributing step (dotted lines). 
Figure 14. Evolution of the intensity of the FTIR absorption bands at $3050 \mathrm{~cm}^{-1}$ and 2950 $\mathrm{cm}^{-1}$, corresponding to the aromatic $\mathrm{C}-\mathrm{H}$ stretching and the $\mathrm{C}-\mathrm{H}$ stretching in methyl or methylene groups respectively, during the degradation of the PS-Cloi20A nanocomposite.

Figure 15. TEM micrographs corresponding to (a) original PS-Cloi20A; (b) the composite after $25 \%$ mass loss and (c) $75 \%$ mass loss. (d) EDX spectra corresponding to the area shown in figure $15 \mathrm{c}$ is also included. 


\section{FIGURE 1}

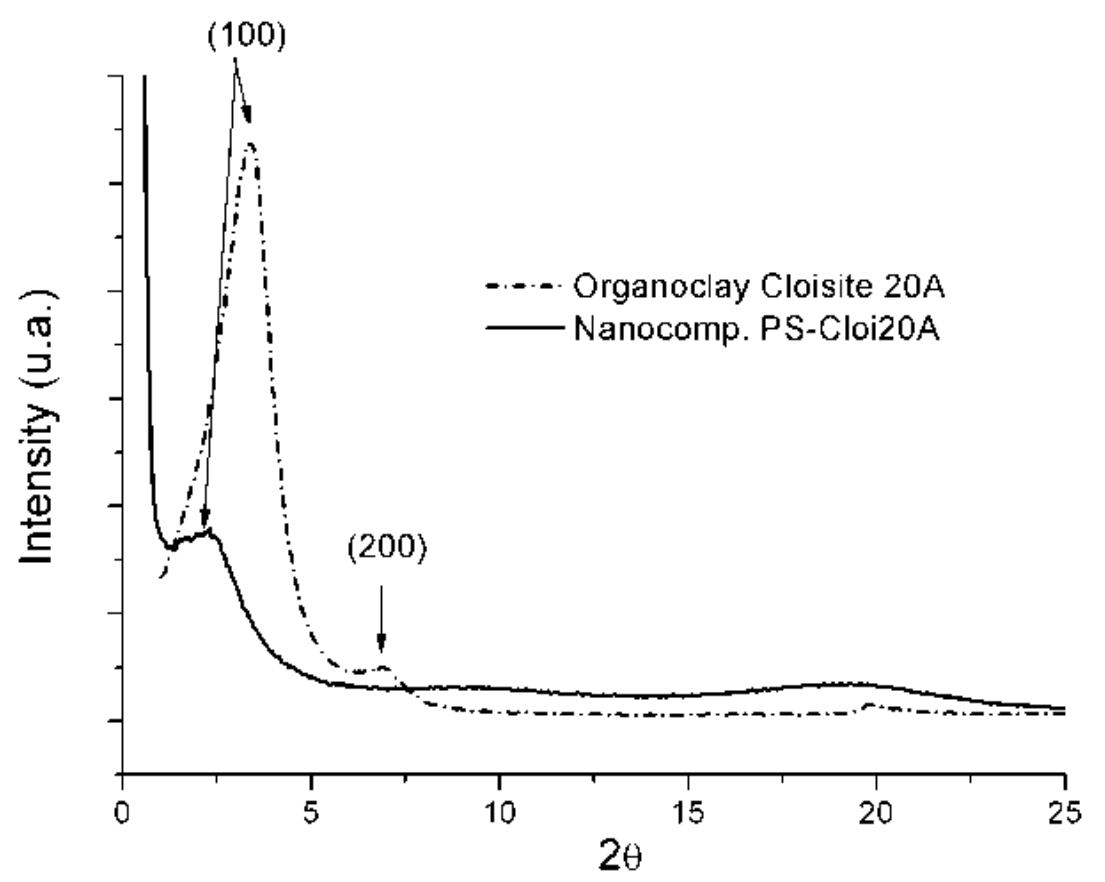

Figure 1. XRD diffractograms of the organophilic Cloisite 20A and PS-Cloi20A nanocomposite. 


\section{FIGURE 2}

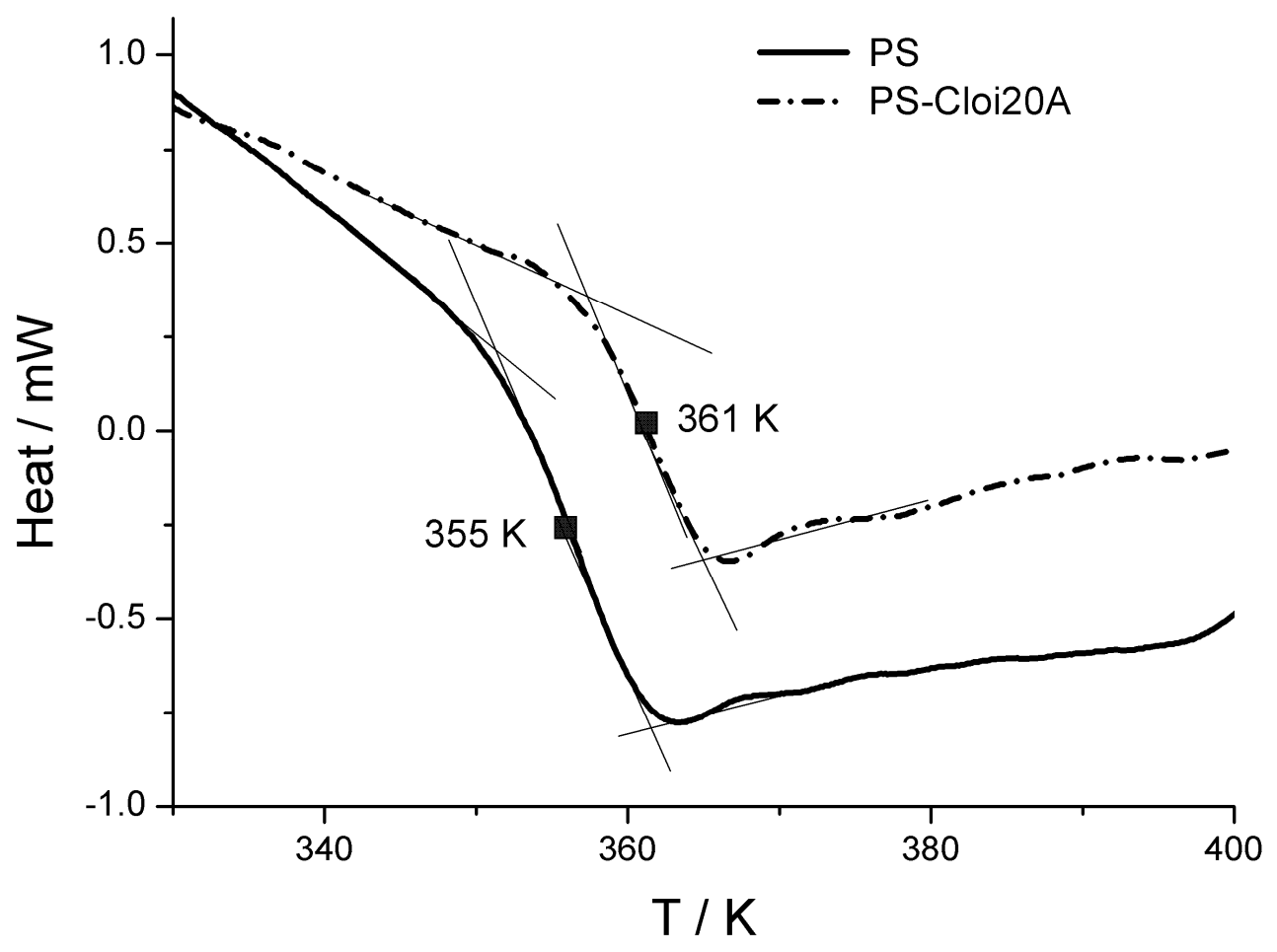

Figure 2. DSC curves corresponding to polystyrene and the PS-Cloi20A nanocomposite. 


\section{FIGURE 3}
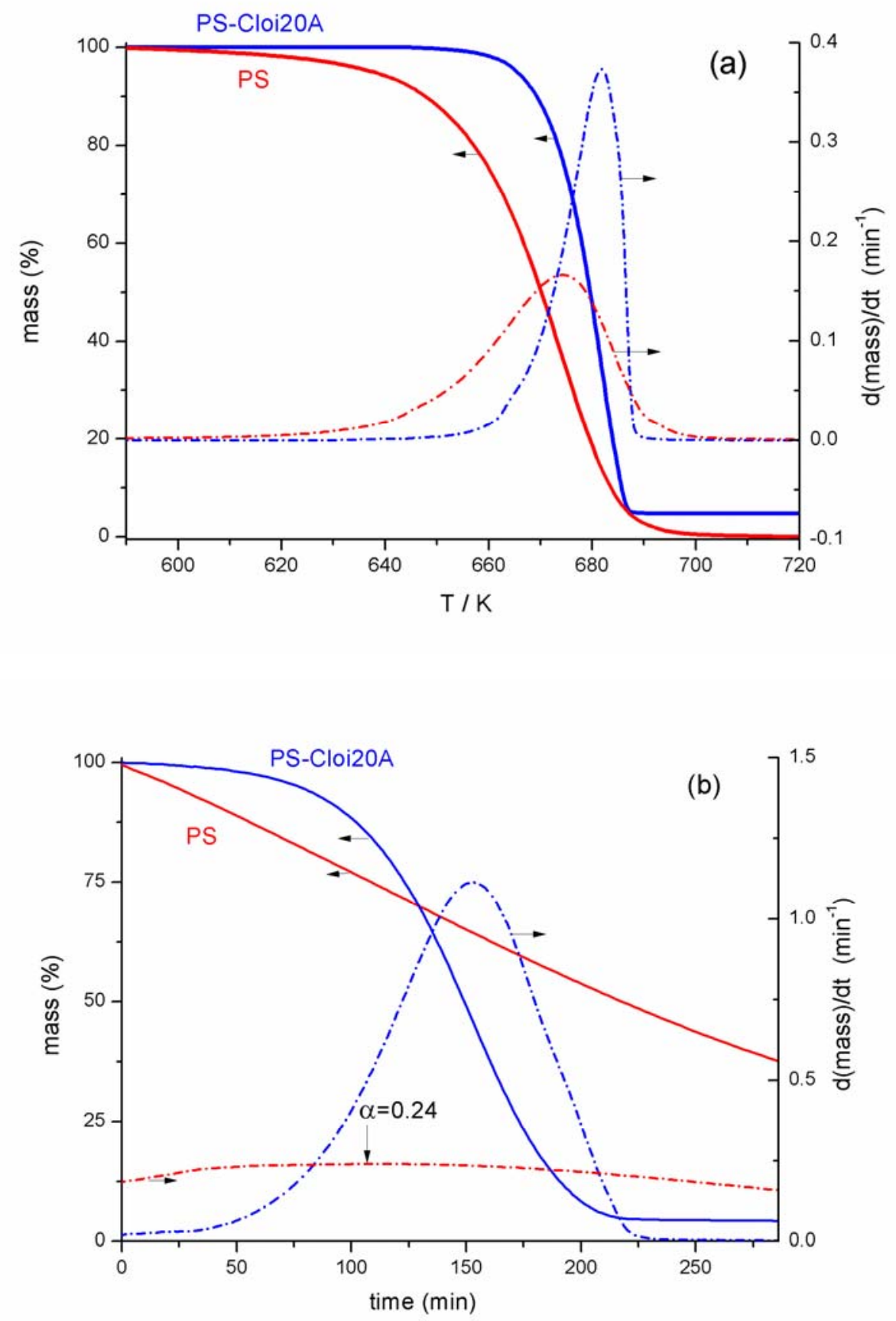

Figure 3. Comparison between the TGA curves corresponding to the degradation of pristine polystyrene and the nanocomposite PS-Cloi20A under (a) linear heating rate at $5 \mathrm{~K} \mathrm{~min}^{-1}$ and (b) isothermal conditions at $593 \mathrm{~K}$. The solid and the dotted lines correspond to the integral TG (mass loss) and to the differential (reaction rate) curves respectively. The maximum of the DTG curve corresponding to the polystyrene curve has been labeled for clarity. 


\section{FIGURE 4}

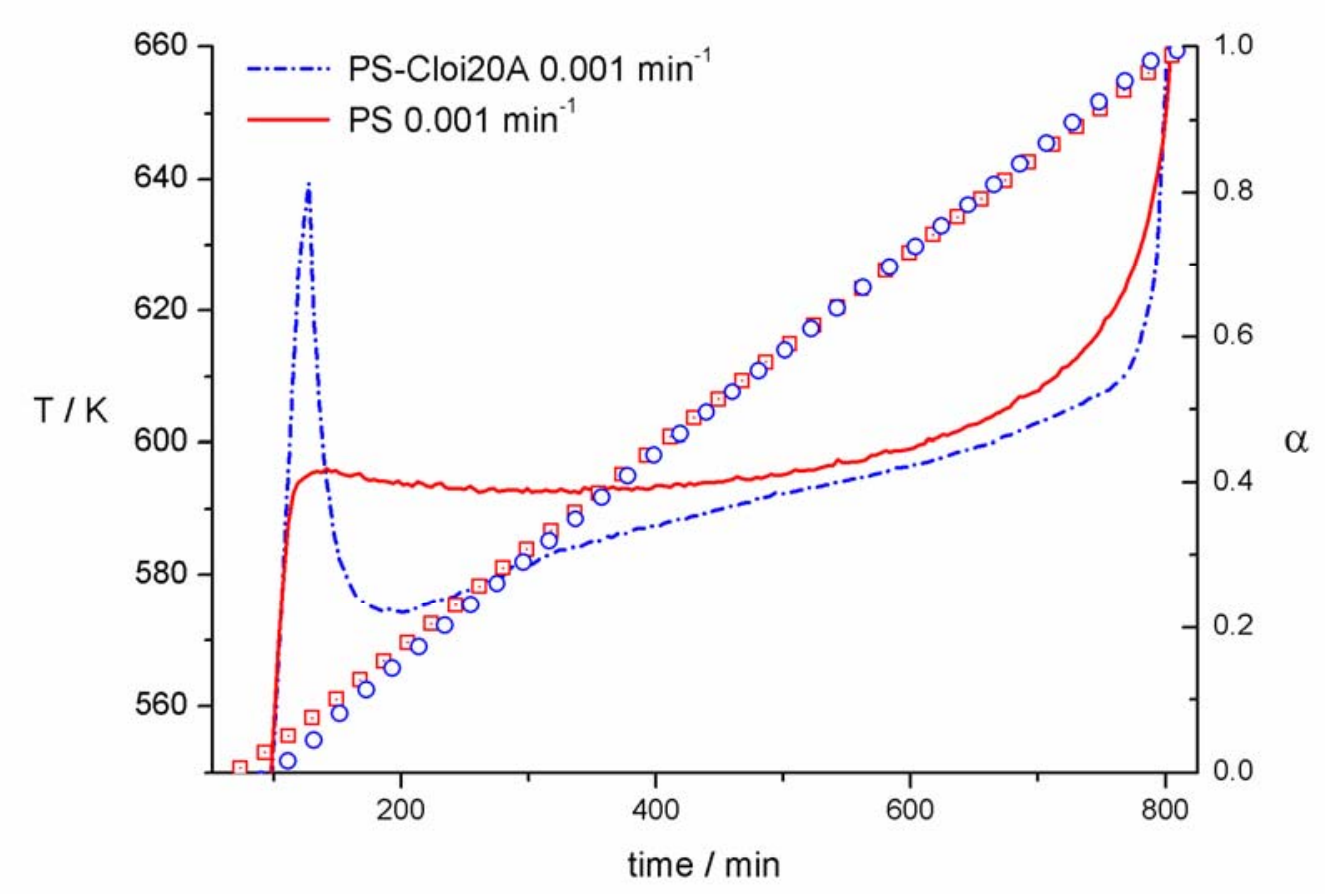

Figure 4. Thermal decompostition curves of polystyrene (solid line) and the nanocomposite PS-

Cloisite20A (dotted line), recorded under CRTA experimental conditions at a constant reaction rate of $0.001 \mathrm{~min}^{-1}$. The conversion versus time plots are shown as symbols. 


\section{FIGURE 5}

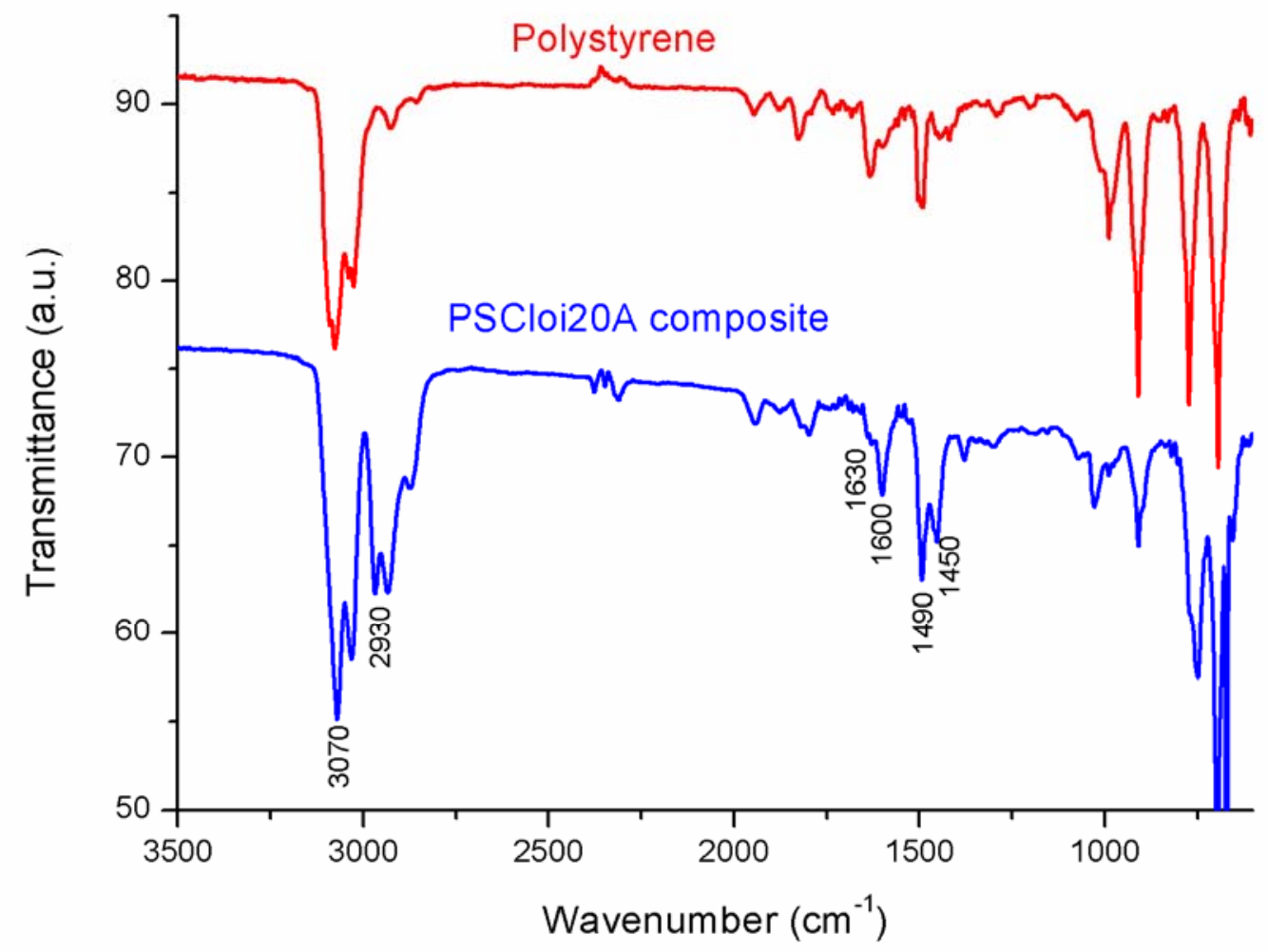

Figure 5. FTIR spectra of the evolved products released during the degradation of pure polystyrene and the composite PS-Cloi20A 


\section{FIGURE 6}

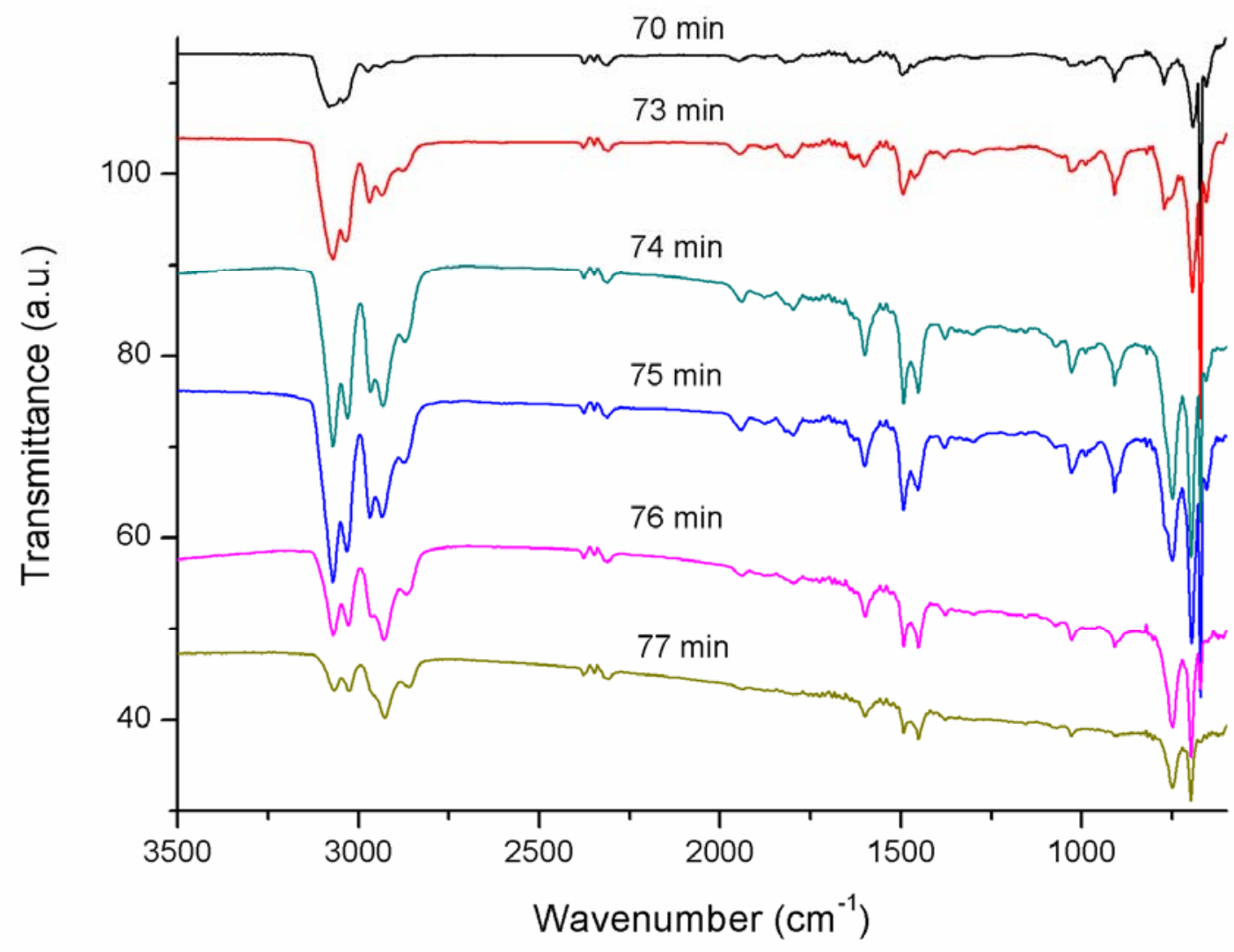

Figure 6. FTIR spectra of the evolved products released during the degradation of the nanocomposite PS-Cloi20A as a function of the reaction time. 


\section{FIGURE 7}
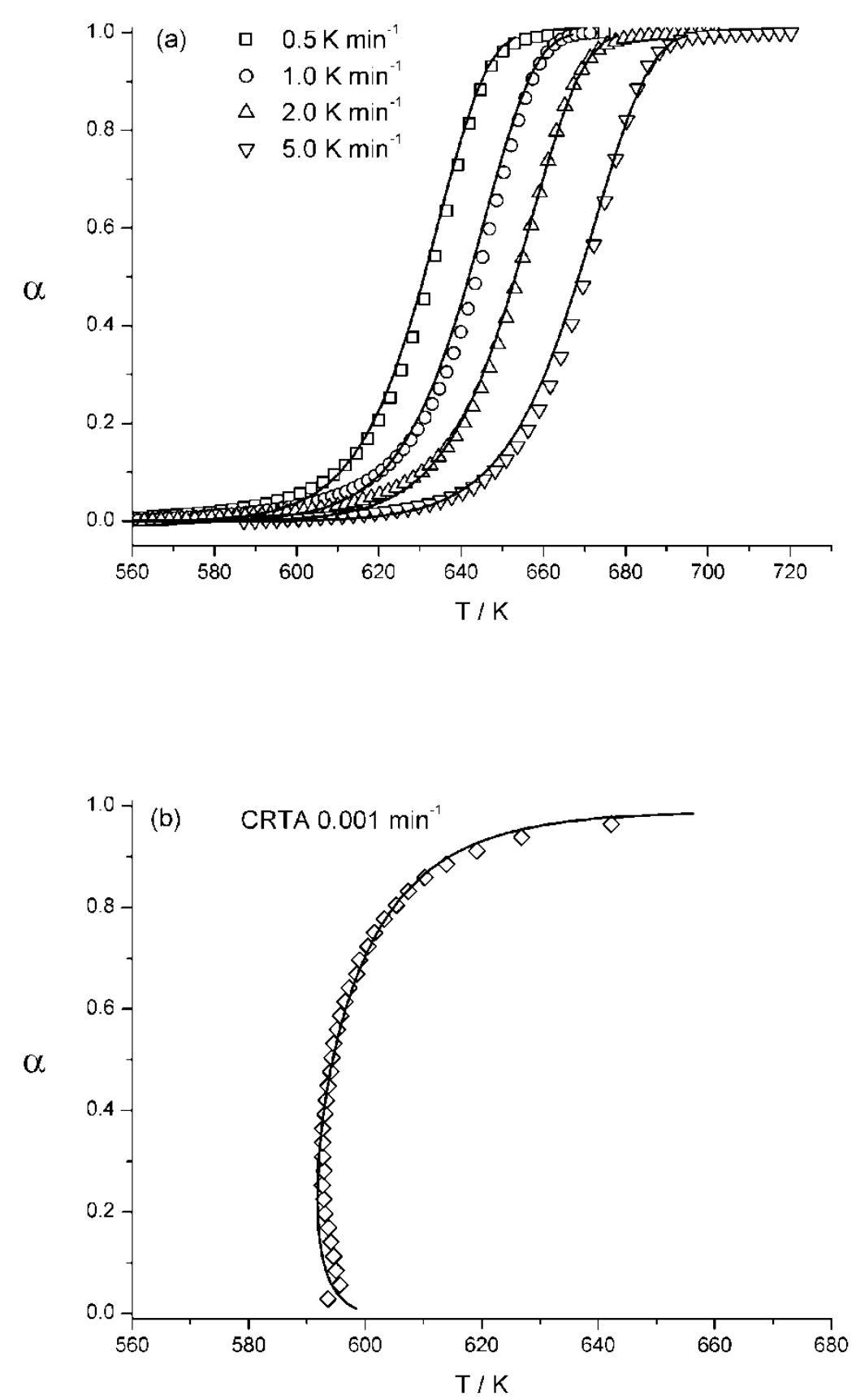

Figure 7. Thermal decompostition curves of polystyrene (symbols) corresponding to experiments run under (a) linear heating rate and (b) controlled rate conditions. The solid lines correspond to the curves reconstructed using the kinetic parameters obtained from the combined kinetic analysis in Section 3.3. 


\section{FIGURE 8}

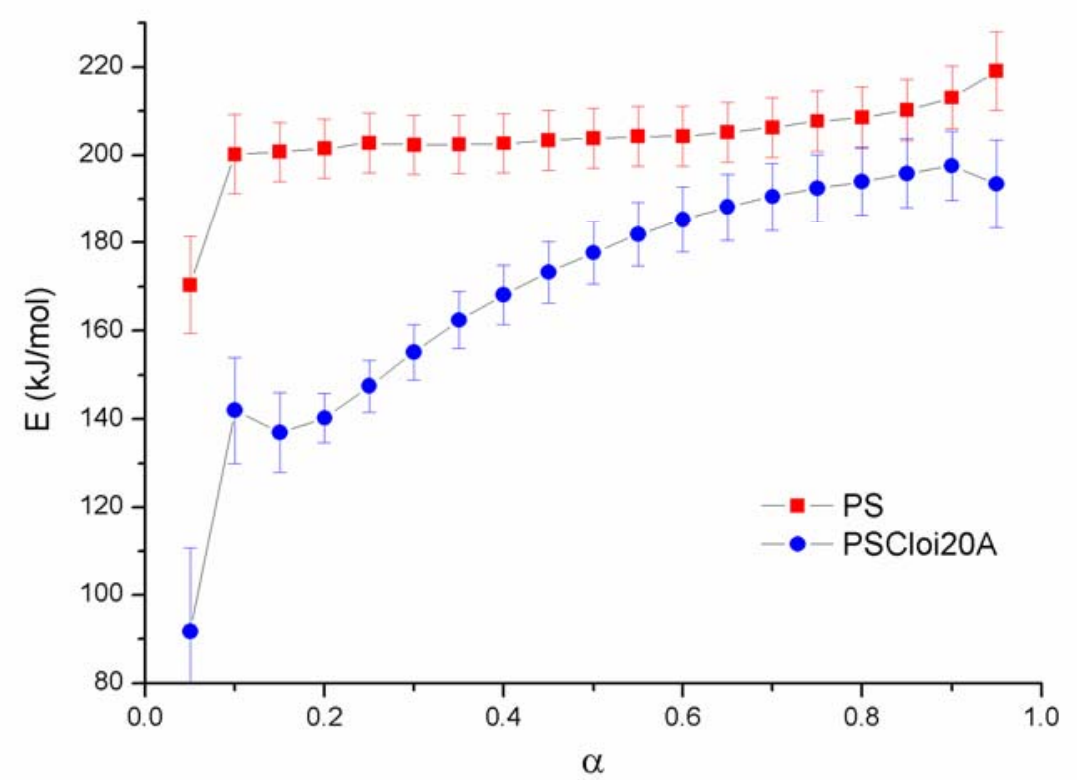

Figure 8. Apparent activation energies at different conversion values as determined by the Friedman isoconversional method using experimental data from the degradation curves included in Figures 7 and 11. 


\section{FIGURE 9}

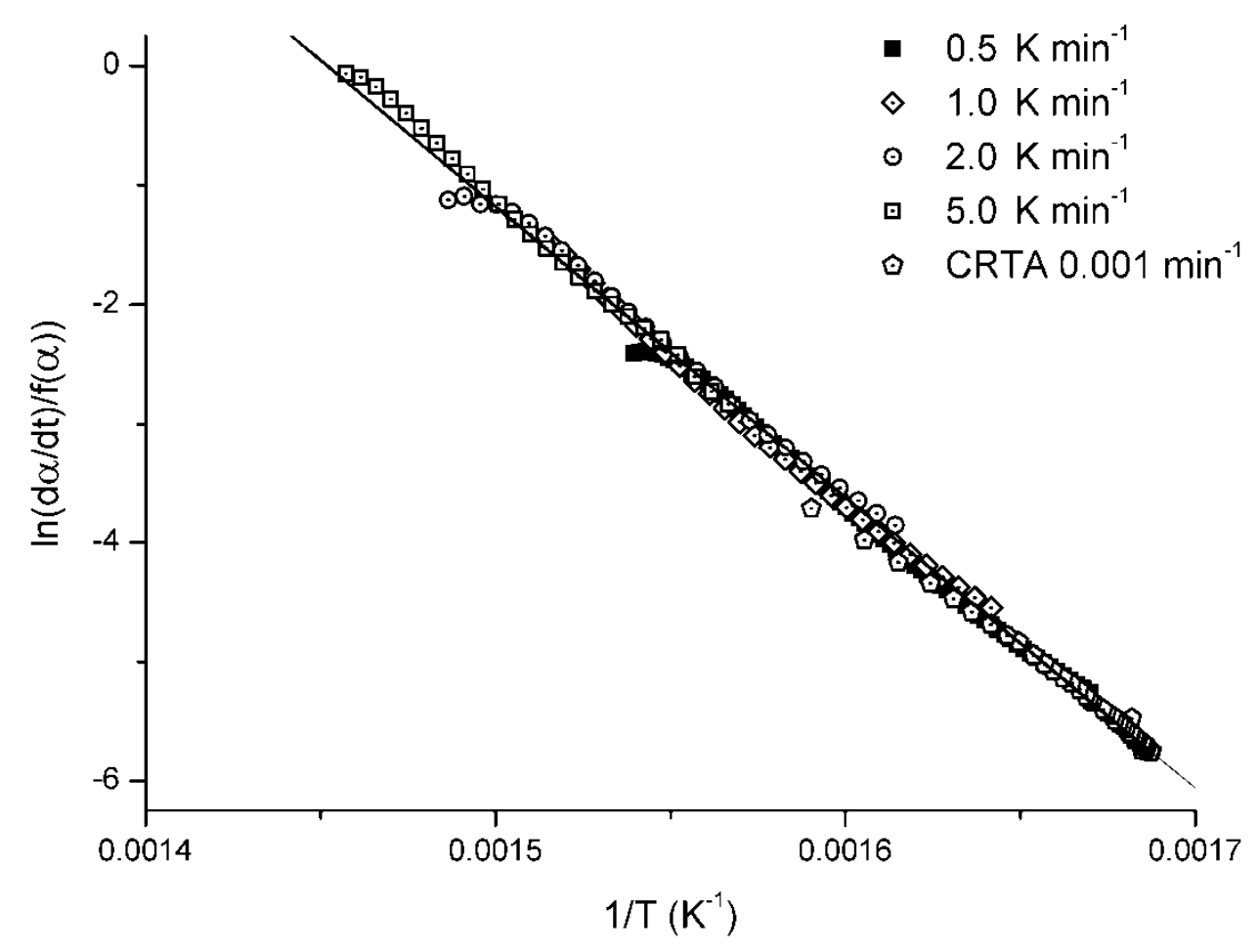

Figure 9. Results of the Combined Kinetic Analysis of the polystyrene degradation curves in figure

7. All the experimental data fits to a straight line when the following kinetic parameters are used: $f(\alpha)=\alpha^{0.28}(1-\alpha)^{0.901}, \mathrm{E}=204 \mathrm{~kJ} \mathrm{~mol}^{-1}$ and $\mathrm{A}=2.710^{15} \mathrm{~min}^{-1}$. 


\section{FIGURE 10}

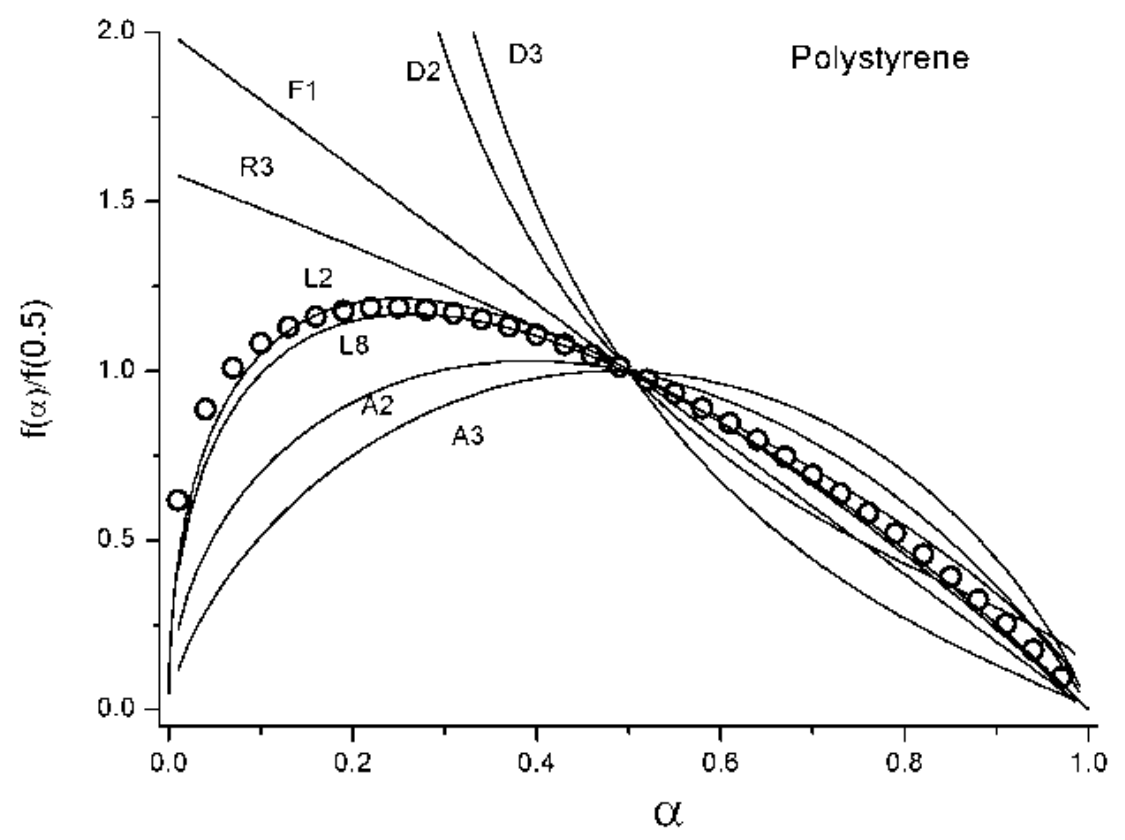

Figure 10. Comparison of the $f(\alpha)$ functions (lines) normalized at $\alpha=0.5$ corresponding to some of the most widely used ideal kinetic models with the $f(\alpha)$ equation (circles), $\alpha^{0.28}(1-\alpha)^{0.901}$, as determined for the thermal decomposition of polystyrene by the Combined Kinetic Analysis. 


\section{FIGURE 11}
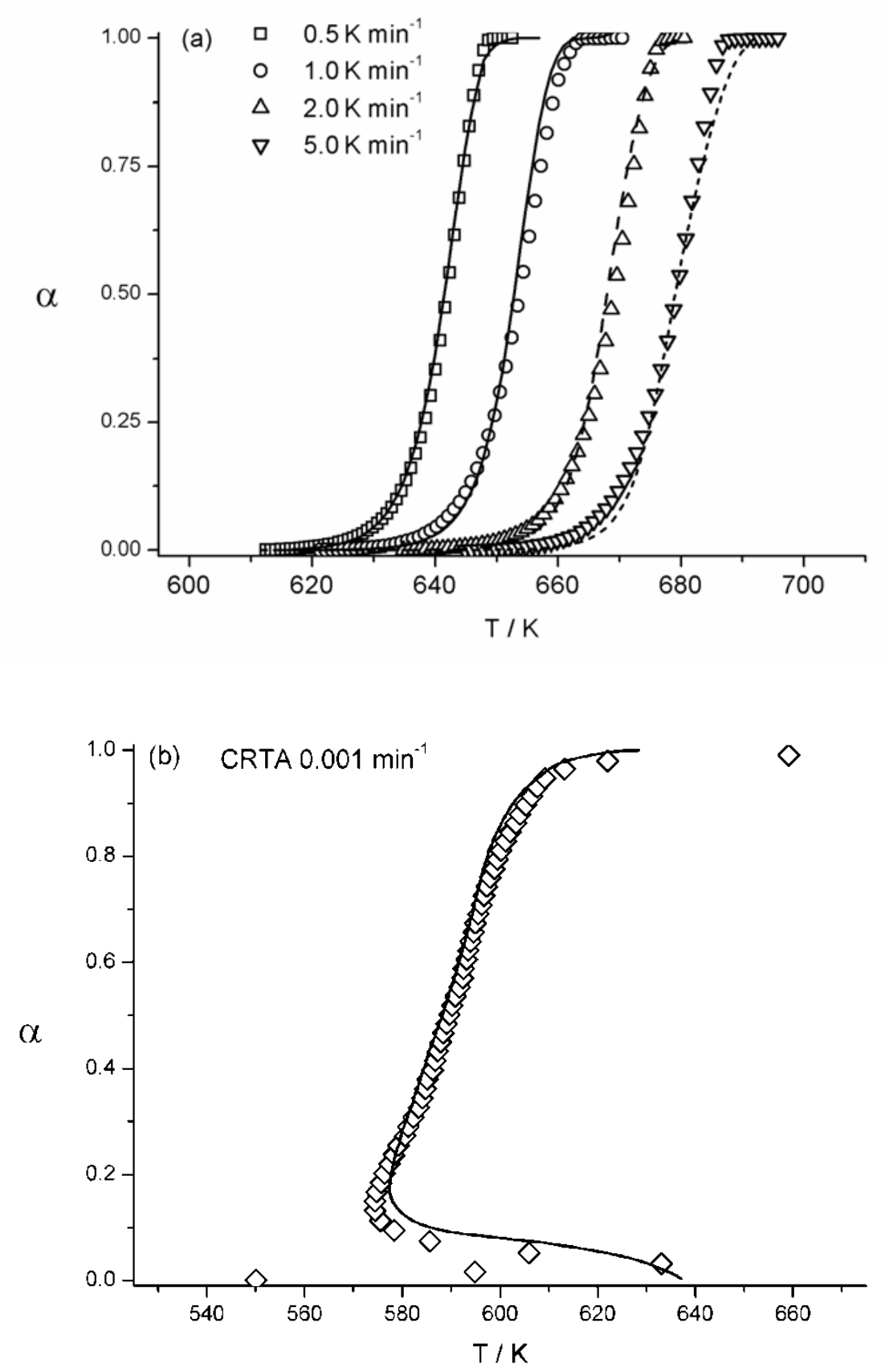

Figure 11. Thermal decompostition curves of the nanocomposite PS-Cloi20A (symbols) corresponding to experiments run under (a) linear heating rate and (b) controlled rate conditions. The solid lines correspond to the curves reconstructed using the kinetic parameters obtained from the combined kinetic analysis performed in Section 3.4. 


\section{FIGURE 12}

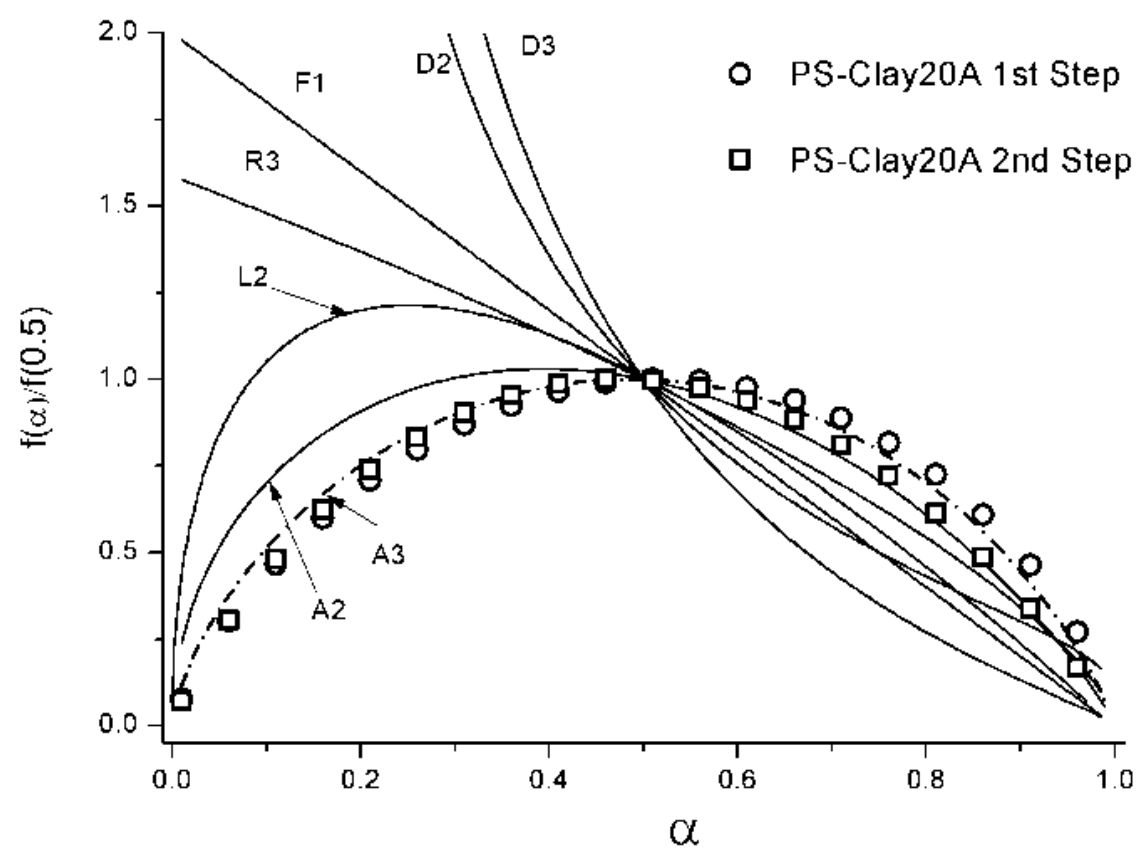

Figure 12. Comparison of the $f(\alpha)$ functions (lines) normalized at $\alpha=0.5$ corresponding to some of the most widely used ideal kinetic models with the $f(\alpha)$ equations (symbols) determined for the first and second stages composing the degradation of the PS-Cloi20A composite, that is $\alpha^{0.720}(1-\alpha)^{0.778}$ and $\alpha^{0.922}(1-\alpha)^{0.834}$ respectively. 


\section{FIGURE 13}

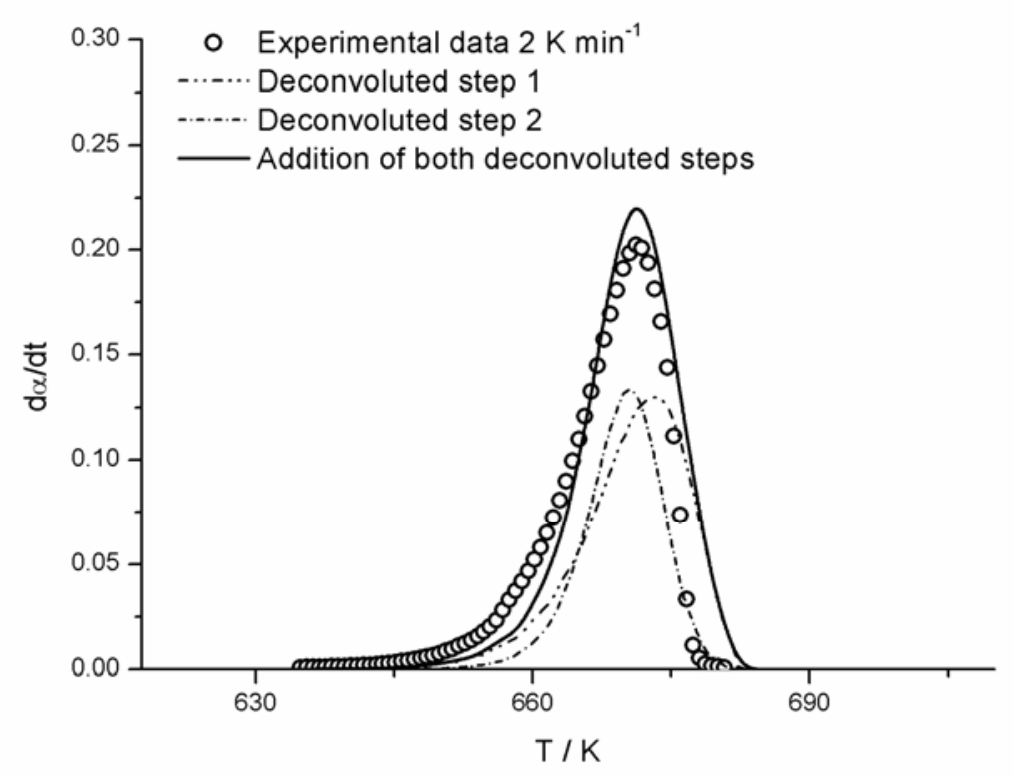

Figure 13. Comparison between the experimental curve corresponding to the complex degradation of the PS-Cloi20A nanocomposite (open circles) and the reconstructed DTG curve (solid lines) obtained by the addition of the DTG curves deduced for each contributing step (dotted lines). 


\section{FIGURE 14}

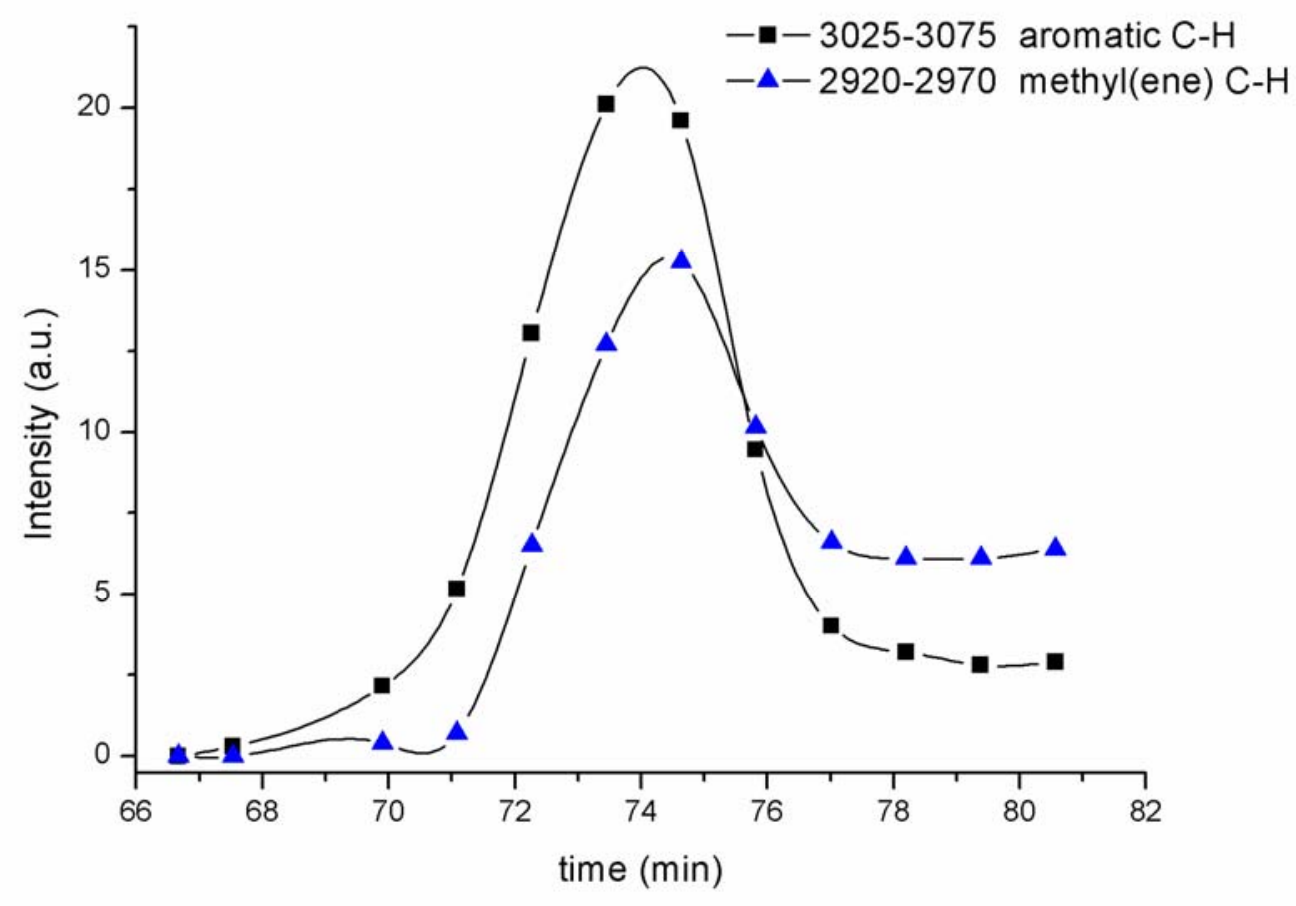

Figure 14. Evolution of the intensity of the FTIR absorption bands at $3050 \mathrm{~cm}^{-1}$ and 2950 $\mathrm{cm}^{-1}$, corresponding to the aromatic $\mathrm{C}-\mathrm{H}$ stretching and the $\mathrm{C}-\mathrm{H}$ stretching in methyl or methylene groups respectively, during the degradation of the PS-Cloi20A nanocomposite. 


\section{FIGURE 15}

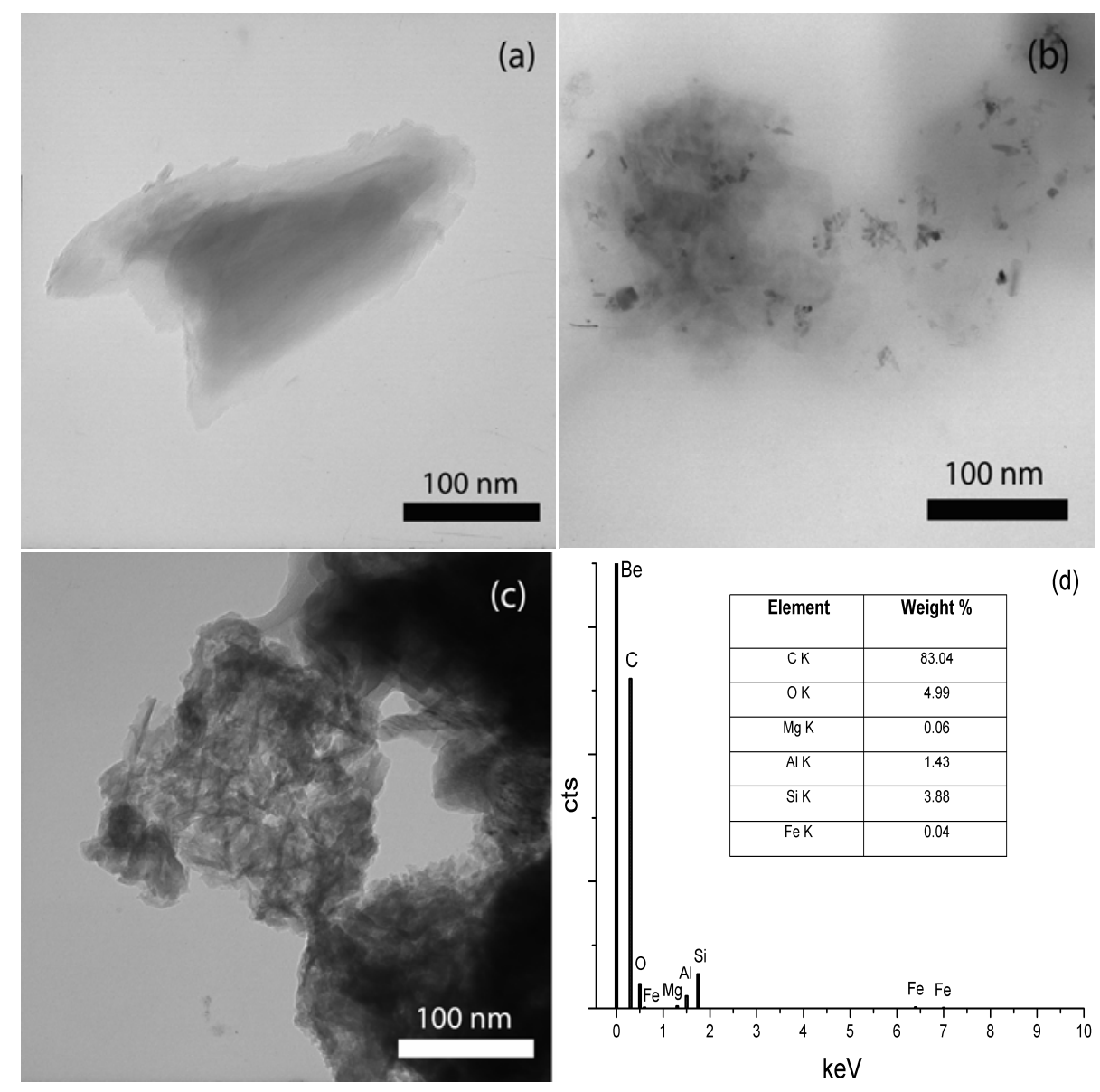

Figure 15. TEM micrographs corresponding to (a) original PS-Cloi20A; (b) the composite after $20 \%$ mass loss and (c) $60 \%$ mass loss. (d) EDX spectra corresponding to the area shown in figure $15 \mathrm{c}$ is also included. 


\section{TABLE OF CONTENTS}

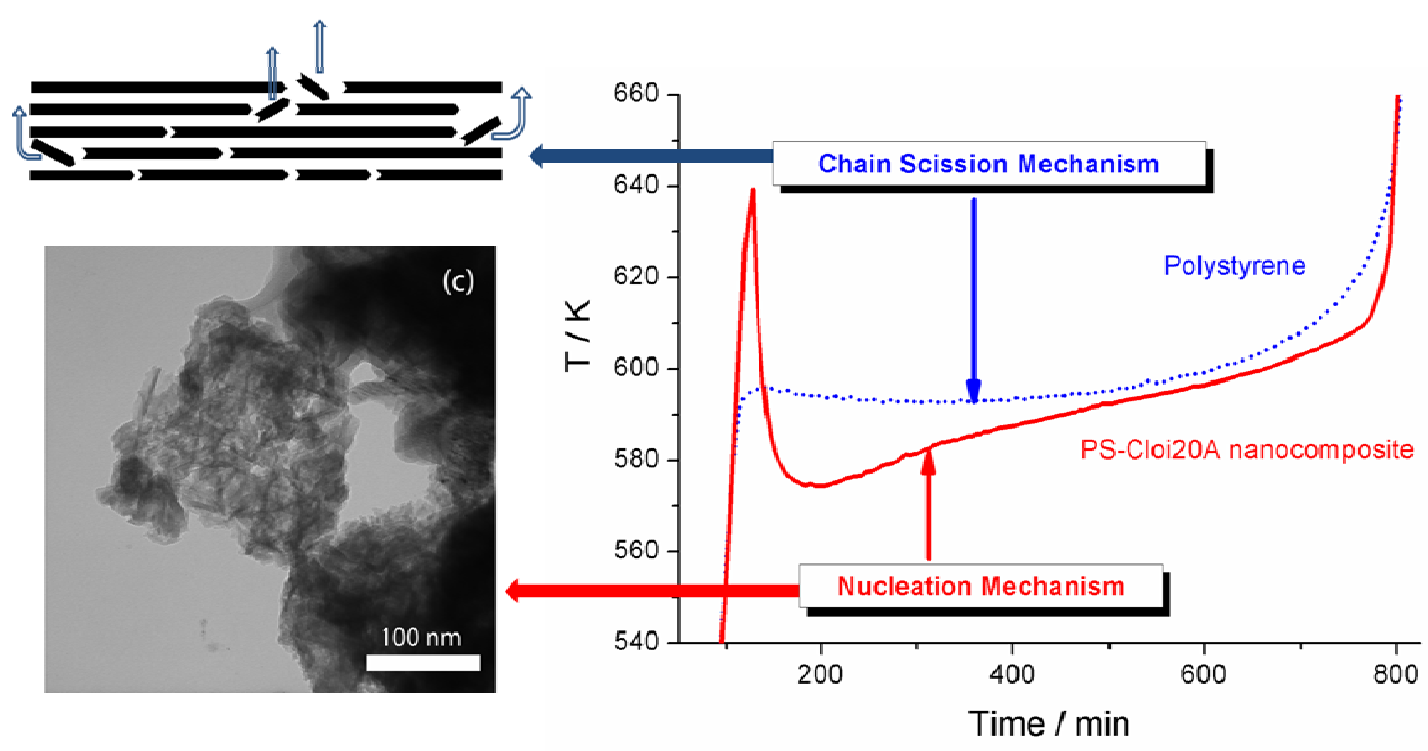

